2021-01-15

\title{
On the impact of motion-thrust coupling in floating tidal energy applications
}

\author{
Brown, Scott Andrew
}

http://hdl.handle.net/10026.1/16651

10.1016/j.apenergy.2020.116246

Applied Energy

Elsevier

All content in PEARL is protected by copyright law. Author manuscripts are made available in accordance with publisher policies. Please cite only the published version using the details provided on the item record or document. In the absence of an open licence (e.g. Creative Commons), permissions for further reuse of content should be sought from the publisher or author. 


\title{
On the impact of motion-thrust coupling in floating tidal energy applications
}

\author{
S.A. Brown ${ }^{\mathrm{a}, *}$, E.J. Ransley ${ }^{\mathrm{a}}$, N. Xie ${ }^{\mathrm{a}, 1}$, K. Monk ${ }^{\mathrm{a}}$, G.M. De Angelis ${ }^{\mathrm{a}}$, R. Nicholls-Lee ${ }^{\mathrm{c}, 2}$, E. Guerrini ${ }^{\mathrm{b}}$, D.M. Greaves ${ }^{\mathrm{a}}$ \\ ${ }^{a}$ School of Engineering, Computing and Mathematics, University of Plymouth, Plymouth, United Kingdom \\ ${ }^{b}$ Modular Tide Generators Ltd., Ramsgate, United Kingdom \\ ${ }^{c}$ Whiskerstay Ltd., Falmouth, United Kingdom
}

\begin{abstract}
Floating systems provide an opportunity to expand the available tidal stream energy resource and reduce the levelised cost of energy by increasing the number of viable deployment sites; simplifying the installation, maintenance and decommissioning; and by accessing greater flow speeds near the free surface. However, the inevitable exposure to free surface conditions raises questions over both the power delivery and the survivability of these systems, both due to the presence of waves and the associated excitation of the floating structures. Without addressing these concerns through scale modelling in laboratories and prototype deployments, the risk to investors is too high to gain significant support for the industry. Therefore, this paper presents physical modelling and analysis of a 1:12 scale model of the Modular Tide Generators floating tidal platform concept, a pseudo-generic design consisting of a catamaran-style platform, catenary mooring system and a submerged horizontal axis tidal turbine. The behaviour of the full system is explored in a range of wave, current, and following wave-current conditions; with and without the turbine; and in rigidly fixed and moored configurations. The results imply that a linear superposition of waves and currents is an adequate modelling approach for determining the mean and cyclic values for the mooring loads and motion of the system. However, the loading on, and power generated by, the turbine are more complex and have implications for power delivery quality and the lifespan of the turbine. In particular, the magnitude of the cyclic loading increases with the current speed, as well as the surge and pitch motion which is observed to be most influential near harmonics of the pitch resonance frequency.
\end{abstract}

Keywords:

Cyclic Loading, Fatigue, Power Generation, Mean Performance, COAST Laboratory, Mooring Design

\section{Introduction}

In the development of a diverse and sustainable energy system, tidal stream represents an Offshore Renewable Energy (ORE) source with a number of desirable characteristics: it is more predictable than other sources (such as wind and wave energy) [51] providing simplified power grid management; the resource tends to be concentrated by topography resulting in desirable sites with high energy densities close to land masses [27] (relatively close to end users compared to distant offshore wind installations), reducing costs in terms of installation and maintenance as well as cabling [7]; the majority of present device concepts, particularly Horizontal Axis Tidal Turbines (HATTs), benefit from technology that has been developed through existing industries, such as hydro and wind power, accelerating the maturity of the tidal stream industry $[4,20]$. However,

\footnotetext{
${ }^{*}$ Corresponding author

Email address: scott.brown@plymouth.ac.uk (S.A. Brown)

${ }^{1}$ Present Address: Department of Engineering, Saipem (UK) Ltd., Kingston upon Thames, United Kingdom

${ }^{2}$ Present Address: College of Engineering, Mathematics and Physical Sciences, Renewable Energy Group, University of Exeter, Penryn, United Kingdom
}

the majority of the proposed tidal stream devices (particularly those with the highest level of technology readiness) tend to be seabed-mounted or gravity-based devices [51]. Use of these concepts limits the number of viable sites as the water depth has to fall within a narrow range, due to constraints on the installation and the required clearance above the turbine blades, and the bathymetry has to be favourable, i.e. relatively flat and horizontal [20]. Furthermore, due to boundary layer effects, the flow speed at depth tends to be lower [14] and, hence, seabed mounted devices do not exploit the full tidal stream resource at the site. Finally, seabed-mounted devices tend to suffer from time-consuming and difficult installation, maintenance and recovery procedures, greatly increasing the overall cost of the projects [51]. Consequently, a number of floating tidal stream concepts have been proposed [51], which have a number of distinct advantages over seabedmounted devices. Floating devices are less limited by water depth, bathymetry or the presence of mobile sediments resulting in a greater number of potential sites and so a higher potential extractable resource [49]. Floating devices also benefit from positioning the turbine towards the top of the water column where the flow velocity is maximum, again increasing the available resource compared to 
seabed-mounted devices [28]. In addition to this, floating tidal stream concepts tend to be easier and quicker to install, maintain and recover [49] as the majority of them can be towed to site using basic tug boats, reducing the need for expensive specialist vessels [26]. However, despite the advantages of floating tidal stream concepts, they require additional considerations to be made regarding their location at the free-surface: firstly, these devices have an additional impact on other stakeholders at the site, e.g. obstruction of navigation and visibility issues; and secondly, the visual impact of the device must be minimised, since it has previously been heavily linked with public acceptance of renewable energy devices $[13,11]$. On the technical impacts of floating tidal systems, the exposure to free-surface effects and waves leads to concerns [49] over power delivery [37, 46]; survivability [15]; and longevity of the devices $[16,17]$. With so few deployments and limited operating hours to date, the effect of proximity to the free-surface and wave loading on these devices is presently not well understood and crucial, under-pinning research is required before these devices will become commercially viable.

This fundamental research can be split into two distinctly different considerations: mean behaviour, relating to long-term performance and typical loading on the system; and cyclic behaviour, linked with accelerated fatigue $[17,10]$, and potential complications in the power delivery $[42,21]$. The cost-competitiveness of floating tidal stream technologies will depend heavily on both the mean and cyclic behaviour since they provide key input parameters to Levelised Cost of Energy (LCOE) models. In particular, for the mean quantities, annual energy production will be highly dependent on the mean power over a wave cycle, whereas component costs will increase if the mean typical design loads increase due to the presence of the turbine. The cyclic loading, Centre of Effort (CoE) and associated bending moment, will accelerate fatigue, reducing the lifespan of components and negatively impacting the LCOE of the device, due to the cost of the new components as well as increased installation/maintenance time and downtime $[48,34]$. Understanding how the proximity of the free surface affects each of these mean and cyclic parameters is key to developing, verifying and validating suitable numerical models to provide accurate inputs to LCOE models and hence determine a more reliable estimate for the cost-competitiveness of floating tidal stream concepts. There are multiple points to address in order to achieve this. Firstly, the flow conditions induced by the waves will directly drive the cyclic loading and motion of the device, but it may also alter mean power output and loading due to wave-current interaction or changes in mean flow speed caused by Stokes Drift [33], a well known mean second-order flow occurring in the direction of wave propagation that is caused by non-closed particle orbits $[45,31]$. Secondly, wave-induced platform motion could lead to changes in the apparent flow speed observed over the turbine, and consequently the power output; a complication which has not needed to be considered in fixed

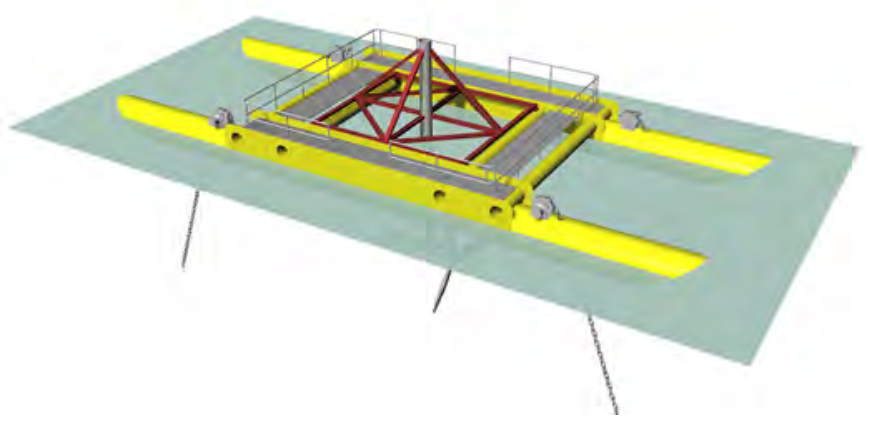

Figure 1: The two-hull MTG concept: Catamaran-style platform, modular HATT and four point catenary mooring system.

seabed-mounted devices. The magnitude of this alteration is likely to be complicated by high sensitivity to incident wave frequency, along with the relative phase of the response compared to the wave, potentially leading to substantially magnified cyclic oscillations under certain conditions. Finally, combining the increased current speeds near the free surface with the additional drag from the turbine is likely to lead to an offset in surge equilibrium position, and consequently an increase (reduction) in the bow (aft) mooring loads.

As with other emerging ORE industries, modelling (both physical and numerical) has become an essential part of the development process. Considerable research effort has already been exerted on characterising the individual components of tidal (and other ORE) concepts in isolation and simplified flow conditions using physical modelling, including: moorings; floating structures; and tidal turbines [12]. This has led to suitable benchmarks for numerical modelling in simplified conditions (i.e. wave-only or currentonly) [3, 41] and, consequently, the development of robust, validated numerical techniques for predicting the loading, response and performance of the individual components in these simplified conditions. However, rarely have all components of a floating tidal stream concept been considered simultaneously as part of a complete physical model, and this leads to uncertainty in whether the coupling between the components is important: For example, does the motion of the platform substantially affect the mean or cyclic performance of the turbine, or can this behaviour be accurately predicted by modelling the turbine alone as a static structure? Until physical data for full floating tidal systems is more readily available (either from deployed prototypes, or scale modelling from laboratories), these questions will remain unanswered; the suitability of existing decoupled numerical model techniques will be unknown due to lack of benchmarking tests; and hence, any predictions from existing decoupled approaches, used as part of the design process, will contain considerable uncertainty.

Therefore, the primary objective of the present study is to analyse the behaviour and performance of a complete floating tidal stream device in realistic flow conditions through scale modelling in a laboratory, and pro- 
vide a physical dataset for future benchmarking of numerical models. This is achieved via a thorough experimental campaign focusing on the Modular Tide Generators (MTG) floating tidal stream concept [40], devised to inform design decisions prior to a planned full-scale prototype deployment. The MTG concept is comprised of a catamaran-style platform with a submerged HATT, designed as a modular component to allow simplified removal/installation for maintenance, and a four-point catenary mooring system (Figure 1). Since the MTG concept has many similarities with other suggested concepts $[22,38]$, it is considered to be a pseudo-generic design for floating tidal stream devices and hence conclusions from the present work are transferable to other developers. To thoroughly assess any changes in the performance and loading of the MTG device arising from a combination of wave-current conditions, presence of the turbine, and motion of the platform, an incremental experimental campaign was conducted where the complexity of both the floating tidal device and the flow conditions were increased following a controlled approach (Table 1). This allows for isolation of particular behaviours so that coupling between the different variables can be identified. Due to difficulties that arise from scaling laws, preliminary tests (ID's 1-7 in Table 1) were conducted in a wave flume to identify a suitable turbine model for integration into a model of MTG device, and assess its behaviour in a static and isolated environment (i.e. without the presence of the floating platform which may alter the flow conditions). Once the turbine model was identified, tests with the MTG platform took place in a larger wave basin (ID's 8-23 in Table 1), and considered the model in a number of different configurations. To determine the effect of platform motion on the turbine and mooring loads, and to allow comparison with the global loads on the model, tests were conducted in both a rigid 'fixed' configuration to provide a reference value, and a 'moored' configuration (Table 1) where the device was free to move in Six Degrees Of Freedom (6DOF). To assess the effect of the turbine on platform motion, as well as on the mooring and global loads, tests were conducted with ('loaded') and without ('unloaded') the turbine and support structure in place, for both the fixed and moored configurations (Table 1).

Understanding the performance and behaviour of a floating tidal stream device in combined wave-current flows is a significant challenge, highlighted by the complexity of the hydrodynamics alone which are not fully understood, and are a long-running field of research $[19,24]$. The loading on a fixed tidal turbine in wave-current flows has been the consideration of a small number of physical studies, mostly conducted in either tow tank facilities [32, 33] or wave flumes with current generation capabilities $[18,23]$. The majority presented similar conclusions: Waves do not generally affect the mean power generated by a tidal turbine, nor the mean loading; and waves substantially increase the amplitude of the cyclic loading on a tidal turbine, with the magnitude likely linked to the wave frequency, although

\begin{tabular}{llllll}
\hline \multicolumn{1}{l}{ ID } & Scale Tank & Restraint & Structure & Flow \\
\hline \hline 1 & N/A & Flume & N/A & None & Current-only \\
2 & N/A & Flume N/A & None & Wave-only \\
3 & N/A & Flume N/A & None & Wave-current \\
4 & $1: 33$ & Flume & Fixed & Turbine & Current-only \\
5 & $1: 25$ & Flume & Fixed & Turbine & Current-only \\
6 & $1: 25$ & Flume & Fixed & Turbine & Wave-only \\
7 & $1: 25$ & Flume & Fixed & Turbine & Wave-current \\
\hline 8 & N/A & Basin & N/A & None & Current-only \\
9 & N/A & Basin & N/A & None & Wave-only \\
10 & N/A & Basin & N/A & None & Wave-current \\
11 & $1: 12$ & Basin & Fixed & Turbine & Current-only \\
12 & $1: 12$ & Basin & Fixed & Unloaded & Current-only \\
13 & $1: 12$ & Basin & Fixed & Unloaded & Wave-only \\
14 & $1: 12$ & Basin & Fixed & Unloaded & Wave-current \\
15 & $1: 12$ & Basin & Fixed & Loaded & Current-only \\
16 & $1: 12$ & Basin & Fixed & Loaded & Wave-only \\
17 & $1: 12$ & Basin & Fixed & Loaded & Wave-current \\
18 & $1: 12$ & Basin & Moored & Unloaded & Current-only \\
19 & $1: 12$ & Basin & Moored & Unloaded & Wave-only \\
20 & $1: 12$ & Basin & Moored & Unloaded & Wave-current \\
21 & $1: 12$ & Basin & Moored & Loaded & Current-only \\
22 & $1: 12$ & Basin & Moored & Loaded & Wave-only \\
23 & $1: 12$ & Basin & Moored & Loaded & Wave-current \\
\hline & & & & & \\
\hline
\end{tabular}

Table 1: Details and reference ID numbers for the experimental test program, including: the scale of the experiments; the type of wave tank used; the station-keeping method; the structure that was considered; and the flow conditions.

the extent of the problem is presently not well quantified. Therefore, as a secondary objective, any observed changes in the combined wave-current hydrodynamics (compared with wave or current-only flows), and alterations in their interaction with tidal turbines, will be reported to aid this research effort. To achieve this, the complexity of the flow conditions were also incrementally increased in the experimental campaign (Table 1), starting with currentonly, progressing to regular wave-only, and finally combined wave-current conditions (in-line, following). Each combination of fixed/moored and loaded/unloaded configurations were tested in a wide range of wave frequencies and flow speeds (Table 1), to determine whether there is any dependency on these parameters. The full details of the experimental campaign are presented in Section 2, with results and analysis for the mean and cyclic behaviour given in Sections 3 and 4, respectively. Further discussion is given in Section 5, with conclusions drawn in Section 6 .

\section{Experimental Details}

The experiments took place in the Coastal, Ocean and Sediment Transport (COAST) Laboratory at the University of Plymouth, UK, and were split into two phases. The first phase (Section 2.1) aimed to identify, calibrate and characterise a suitable turbine model for use in a model 


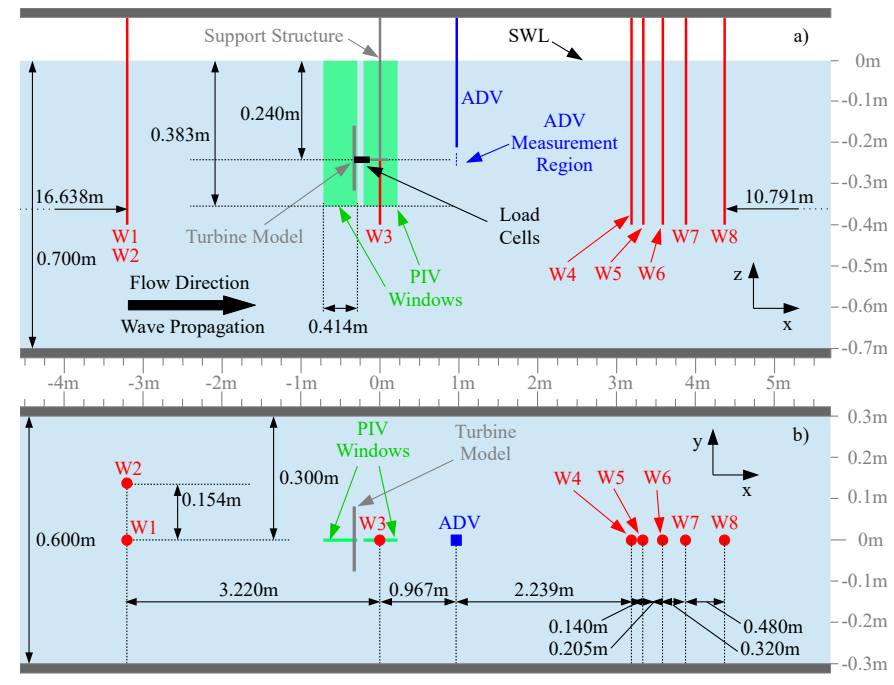

Figure 2: Experimental setup of phase 1 (wave flume) of the experimental campaign in the $x-z(\mathrm{a})$ and $x-y$ (b) planes. The positions of the wave gauges (W), ADV and PIV windows are shown relative to the turbine model.

of the full floating tidal system. The second phase (Section 2.2) focused on evaluating the long-term performance and cyclic behaviour of an entire floating model of the twohull MTG device, including the turbine model identified in the first phase.

\subsection{Phase 1: Turbine Model Characterisation}

Phase 1 of the experimental campaign (ID's 1-7 in Table 1) was conducted in the COAST Laboratory's Sediment Flume, which is $35 \mathrm{~m}$ in length, $0.6 \mathrm{~m}$ wide and was operated with a water depth of $0.7 \mathrm{~m}$. The flume has an installed active absorption wave paddle capable of producing irregular and regular waves; a reversible flow recirculation system which can produce currents greater than $1 \mathrm{~m} / \mathrm{s}$; and glass side panels for flow visualisation purposes. For the purpose of these experiments, the origin is set at the centre of the vertical support structure (Figure 2), and at the Still Water Level (SWL). The coordinate system is defined such that the streamwise component is the $x$-axis, with positive set as the direction of wave propagation; the transverse component is the $y$-axis; and the $z$-axis is the vertical, with upwards as the positive direction (Figure 2).

\subsubsection{Turbine Model, Setup and Instrumentation}

The turbine model used in this work is based on a porous disc (momentum theory [8]) approach, which has been previously demonstrated for other tidal applications $[5,36]$. A series of discs of varying porosity $(35-50 \%)$ were constructed out of $3 \mathrm{~mm}$ aluminium using laser-cutting. The analysis was split into two parts: Firstly tests were conducted in current-only conditions, designed to determine the relationship between disc porosity and characteristic thrust coefficient, $C_{t}$, defined as

$$
C_{t}=\frac{2 T}{\rho A u^{2}},
$$

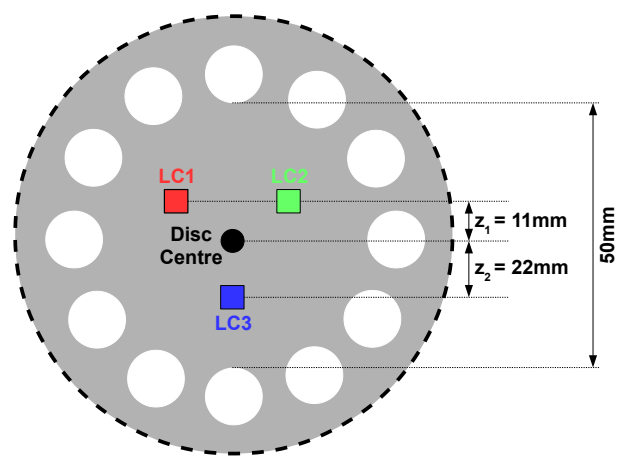

Figure 3: Diagram of the central section of the porous disc showing the setup of the three load cell configuration (LC1-LC3).

where $T$ is the total thrust on the turbine; $\rho$ is the fluid density; $A$ is the area of the turbine; and $u$ is the incident flow speed. In these current-only tests (ID 4 in Table 1), a 1:33 scale porous disc was used (radius, $R=0.06 \mathrm{~m}$ ) to minimise blockage effects, and the load was measured using one waterproof single-axis load cell. Secondly, the behaviour of the disc is considered in wave-current conditions (ID's 5-7 in Table 1). In these tests a larger 1:25 scale $\operatorname{disc}(R=0.08 \mathrm{~m})$ is used. This allows space to include a solid region at the central hub of the disc $(\varnothing 0.05 \mathrm{~m})$ for mounting a load cell configuration, which can also measure the CoE on the disc and hence the bending moment. This load cell configuration is constructed from three waterproof single axis load cells setup as shown in Figure 3, each with an accuracy of $0.15 \%$, and a maximum capacity of $22 \mathrm{~N}$. The total thrust $(T)$ and vertical $\mathrm{CoE}\left(Z_{\text {coe }}\right)$ are calculated as

$$
\begin{array}{r}
T=T_{1}+T_{2}+T_{3}, \\
Z_{\text {coe }}=\frac{1}{T}\left(z_{1}\left(T_{1}+T_{2}\right)-z_{2} T_{3}\right),
\end{array}
$$

where $T_{i}$ is the thrust on the $i^{\text {th }}$ load cell. The bending moment is defined as the product of the thrust and vertical CoE, i.e. $M_{y}=Z_{c o e} T$.

The experimental setup was such that the centre of the turbine model was located $19.858 \mathrm{~m}$ from the wavemaker in the streamwise $(x)$ direction, at the centre of the flume in the transverse $(y)$ direction, and such that the central hub was at a water depth of $0.24 \mathrm{~m}$. The turbine model was rigidly attached to the top of the flume via a support structure constructed from aluminium bar (Figure 2). Wave heights were measured using a series of eight resistance gauges (Figure 2), with the one located at the turbine model support structure (W3) used in this work. Flow velocities were gathered using two methods: Firstly, the $x, y$ and $z$ components were measured at a sampling frequency of $100 \mathrm{~Hz}$ using an Acoustic Doppler Velocimeter $(\mathrm{ADV})$, positioned at the centre of the flume $(y=0 \mathrm{~m})$ downstream of the turbine model $(x=0.967 \mathrm{~m})$ and over a $3 \mathrm{~cm}$ vertical range $(-0.225 \mathrm{~m} \leq z \leq 0.255 \mathrm{~m})$. The second method was a Particle Image Velocimetry (PIV) system, 
which provided a spatial mapping of the $x-z$ velocity plane at the centreline of the turbine $(y=0 \mathrm{~m})$. This system provided a non-intrusive measurement to verify the ADV reading and ensure that any spatial dependency is small. Each wave-current combination was repeated twice to capture the flow velocities upstream and downstream of the turbine model using the PIV system (Figure 2).

\subsubsection{Flow Conditions}

To determine the flow conditions, a series of calibration tests (ID's 1-3 in Table 1) were conducted without the model in place. Four wave frequencies were evaluated $(f=$ $0.42 \mathrm{~Hz}, 0.50 \mathrm{~Hz}, 0.63 \mathrm{~Hz}, 0.83 \mathrm{~Hz})$, with three different wave heights used for each $(H=0.04 \mathrm{~m}, 0.07 \mathrm{~m}, 0.10 \mathrm{~m})$, and each individual run had a total duration of $75 \mathrm{~s}$. A subset of the flow speeds from the current-only cases $(0.00 \mathrm{~m} / \mathrm{s}$ $\leq u \leq 0.66 \mathrm{~m} / \mathrm{s}$ ) were selected for the wave-current cases, in addition to the wave-only data. These were in-line (following) currents with magnitude $u=0.20 \mathrm{~m} / \mathrm{s}, u=0.43 \mathrm{~m} / \mathrm{s}$ and $u=0.66 \mathrm{~m} / \mathrm{s}$.

\subsection{Phase 2: Floating Tidal Stream Model}

Phase 2 of the tests (ID's 8-23 in Table 1) were conducted in the COAST Laboratory's Ocean Basin, a facility that is $35 \mathrm{~m}$ in length, $15.5 \mathrm{~m}$ wide and has an adjustable floor to allow for a range of operating water depths up to a maximum of $3 \mathrm{~m}$. The operational water depth is set to $1 \mathrm{~m}$ in this work, consistent with the full scale depth of Truro River, UK, which is a proposed early stage prototype deployment site for the device. Waves and in-line, following currents were generated using 24 individually controlled hinged flap absorbing paddles, and a recirculating flow

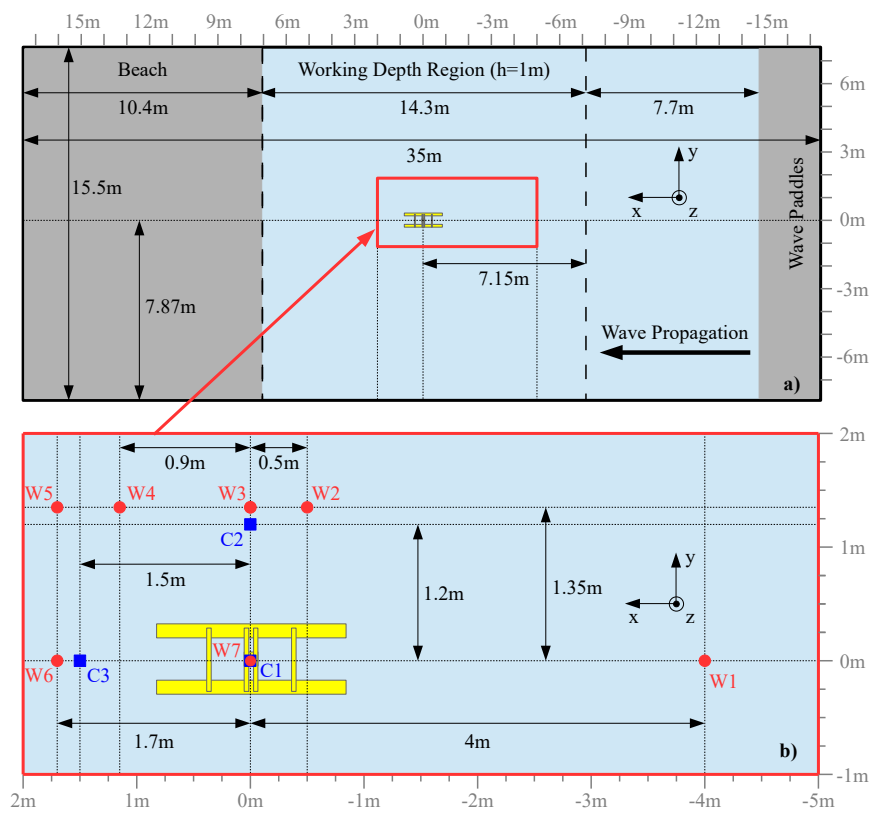

Figure 4: Diagram of the experimental layout in phase 2 (Ocean Basin) of the experiments, including the numbering conventions for the wave gauges $(\bullet)$ and flow meters $(\boldsymbol{\square})$.

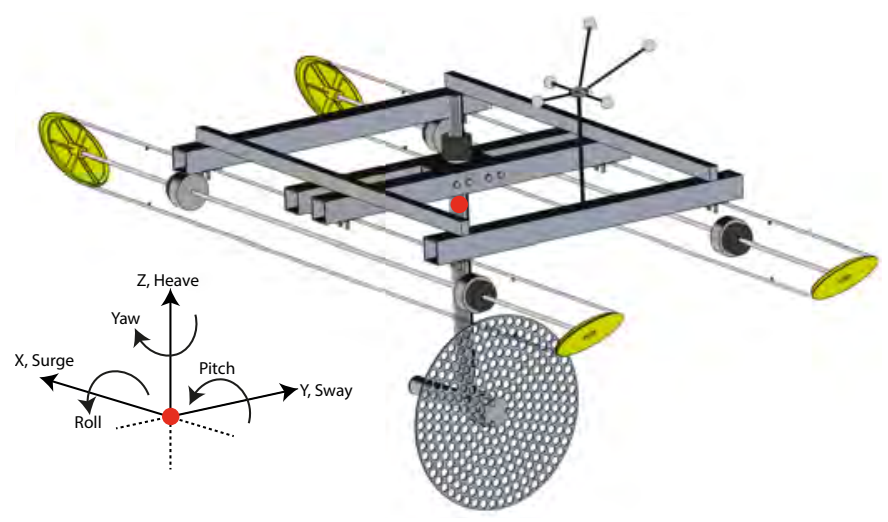

Figure 5: CAD diagram for the 1:12 scale loaded MTG model used in the experimental campaign.

system, respectively. A parabolic beach was utilised at the other end of the tank for wave absorption (Figure 4a). The same coordinate system from Phase 1 (Section 2.1) is used, with the origin set as the centre of the model at the SWL (Figure 4a).

\subsubsection{MTG Model, Setup and Instrumentation}

The two-hull MTG model was manufactured at 1:12 scale based on initial designs of a full scale prototype. The hulls were produced from $100 \mathrm{~mm}$ outer (92 mm inner) diameter polycarbonate tube, with a simplified support structure created from aluminium tube (Figure 5). Ballast was integrated into the hulls so that the mass properties (centre of mass, moment of inertia) of the scale model would match the full scale prototype according to Froude similarity. The model was designed such that it could be considered in the unloaded (i.e. without the turbine model or support structure present) and loaded configurations (Figure 6c-f).

The MTG model was positioned close to the centre of the working depth region of the Ocean Basin (Figure 4a). The motion of the device was recorded using a 6 DOF optical motion tracking system, comprised of nine cameras. Resistive wave gauges and electro-magnetic (EM) flow meters were used to measure the surface elevation and flow velocities, respectively. For calibration tests, without the model in place, wave gauges were installed at seven locations within the tank (W1-W7 in Figure 4b), and two EM flow meters were deployed (C1-C2 in Figure 4b) to measure at a water depth equivalent to the centre of the turbine model. For runs with the model in place, wave gauge W7 was removed and the flow meter position was moved from $\mathrm{C} 1$ to $\mathrm{C} 3$.

The turbine model used in this phase of the experiments was a $\varnothing 0.333 \mathrm{~m}$ porous disc constructed out of $2 \mathrm{~mm}$ aluminium with an overall porosity of $50 \%$ (see Section 3.1), chosen since it most closely matches the characteristics of a proposed turbine design for the full scale prototype. The total thrust and bending moment on the disc were measured using the three load cells configuration 

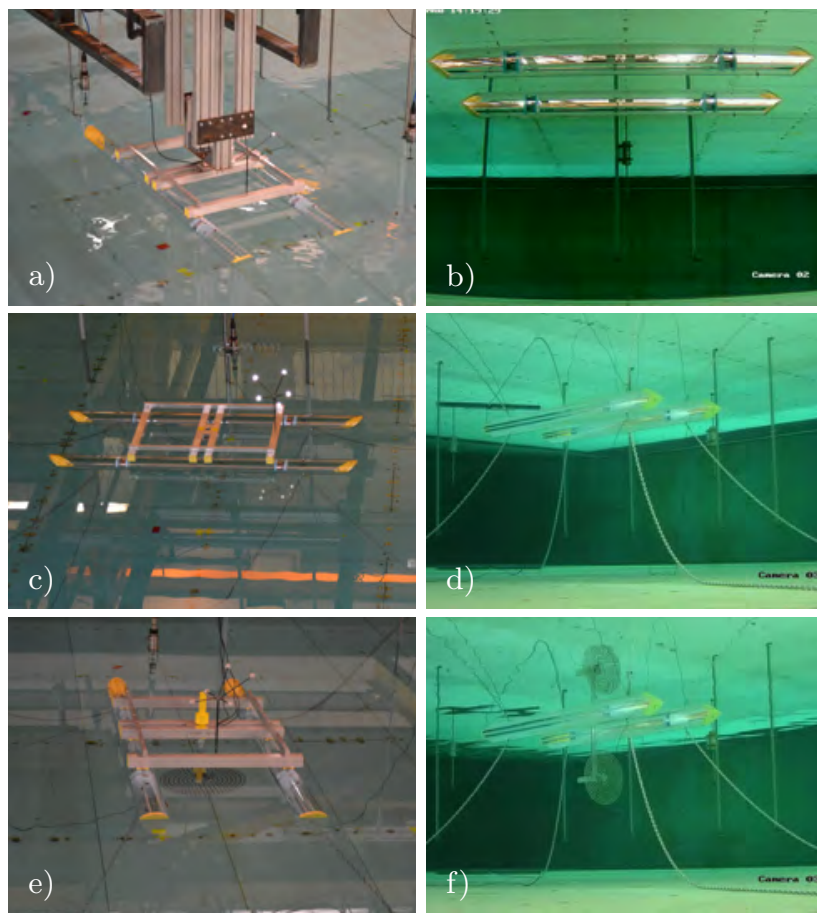

Figure 6: High angle (a,c,e) and underwater (b,d,f) photographs of the different test configurations (see Table 1): fixed, unloaded (a,b); moored, unloaded (c,d); and moored, loaded (e,f).

described in Section 2.1, and the disc was designed to have a small $(\varnothing 0.05 \mathrm{~m})$ solid region around the central hub in order to mount these load cells (Figure 3).

Two station keeping methods were considered in the experiments (Table 1; Figure 6). Firstly, a rigid 'fixed' configuration was utilised to provide the global load on the structure, and to provide a reference for the behaviour of the turbine model without the added complication of the motion of the platform. The fixed configuration was achieved by connecting the model to a rigid structure (Figure 6a) attached to a gantry above the Ocean Basin such that the model was located at the vertical equilibrium position of the moored device. A six-axis load cell was used to attach the model to the rigid structure allowing the total load on the model to be measured. The accuracy of the load cell is $\pm 0.1 \%$, with maximum capacities of $125 \mathrm{~N}$ for $F_{x}$ and $F_{y} ; 250 \mathrm{~N}$ for $F_{z}$; and $25 \mathrm{Nm}$ for all moment components. The other station keeping method was a fourpoint catenary approach (Figure 6d,f), constructed using $0.278 \mathrm{~kg} / \mathrm{m}$ chain (in water), each $4.8 \mathrm{~m}$ in length, and will be referred to as the 'moored' configuration in this work. The mooring lines were spread at $30^{\circ}$ from the longitudinal centreline $(y= \pm 0.26 \mathrm{~m})$ of each hull (Figure 7 ), and were anchored using clump weights. The mooring lines attach to the bottom of the hull via a waterproof single axis load cell with a maximum capacity of $445 \mathrm{~N}$.

\subsubsection{Flow Conditions}

Each run in this phase of the experimental campaign was $120 \mathrm{~s}$ in length with $90 \mathrm{~s}$ of wave generation and an

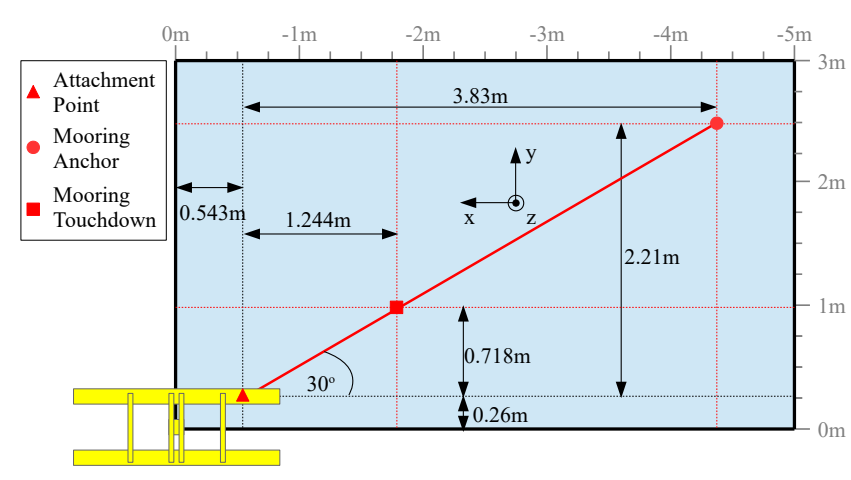

Figure 7: Diagram for the mooring setup in phase 2 (Ocean Basin) of the experiments showing the attachment point $(\boldsymbol{\Delta})$, anchor $(\bullet)$ and theoretical touchdown positions $(\boldsymbol{\square})$ of the port-bow mooring.

extra $30 \mathrm{~s}$ to allow for propagation in the wave-only and wave-current cases. A range of wave frequencies $(0.25 \mathrm{~Hz}$ $\leq f \leq 1.75 \mathrm{~Hz}$ ) were tested, both in wave-only and wavecurrent conditions. Four following current speeds were considered $(0.00 \mathrm{~m} / \mathrm{s} \leq u \leq 0.44 \mathrm{~m} / \mathrm{s})$, with a series of current-only empty-tank (i.e. without the MTG model in place) calibration tests (ID 8 in Table 1 ) conducted to determine the observed flow speeds at location C1 (Figure 4).

The wave heights used in this work were selected to achieve a theoretical steepness of $k a=0.01$ in wave-only conditions, as shown in Figure 8 (linestyle: ......). However, at high and low frequencies it was necessary to limit the lower $(1.4 \mathrm{~cm})$ and upper $(8 \mathrm{~cm})$ wave heights, respectively, due to limitations in the wave generation software. The values that were used as input into the wave generation software are presented in Figure $8(---)$. Note that in wave-current conditions the same input height was used, with the expectation that the measured height would be considerably smaller due to the currents being following [24]. To determine the wave heights which were actually observed in the tank, a series of empty-tank calibration tests (ID's 9-10 in Table 1) were conducted. Results implied that in wave-only conditions, the measured waves were close to the target wave height at both WG1 ( $\Delta)$ and WG7 $(\Delta)$, with little variation in the values recorded at the two locations. As the current speed increases, the wave height is observed to reduce, as expected. The data from the empty tank is used to provide the wave height for normalisation throughout this study, when available. However, to allow a wider range of wave frequency/current conditions to be considered, in-situ data is used when there is no empty tank calibration data available. Since W7 was not available in-situ, the upstream, centreline wave gauge (W1 in Figure 4b; • empty tank; o in-situ) is used in all cases for consistency. This wave gauge was selected since: it provided similar values as W7 in the calibration tests; and it was observed to be the least affected by the presence of the structure, as seen by the generally good agreement with the empty tank data in Figure 8. However, there 


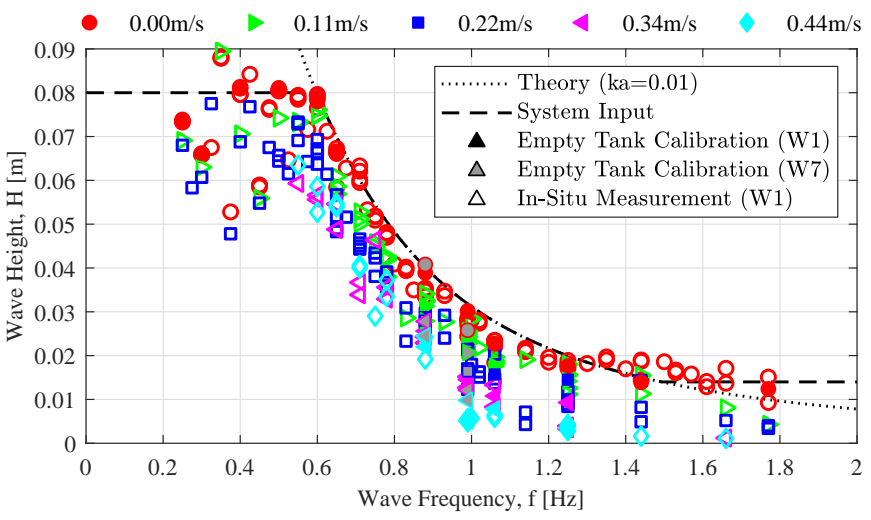

Figure 8: Measured wave heights as a function of frequency. The theoretical wave height based on a steepness of $k a=0.01$ is shown for reference $(\cdots \cdots)$, along with the value that was used as the input for the wave generation software $(---)$. The markers/colours represent the different current speeds: $0.00 \mathrm{~m} / \mathrm{s}(\bullet), 0.11 \mathrm{~m} / \mathrm{s}(\bullet), 0.22 \mathrm{~m} / \mathrm{s}(\boldsymbol{\square})$, $0.34 \mathrm{~m} / \mathrm{s}(\triangleleft), 0.44 \mathrm{~m} / \mathrm{s}(\triangleleft)$.

is some scatter at very low wave frequencies, thought to be due to either tank effects or reflections off the structure, and this should be considered when interpreting the results.

\subsection{Analysis Methods}

In current-only conditions, the full time series for each run is used to calculate the mean values. In wave-only and wave-current conditions, the time series' are truncated to start after five stable waves have passed (calculated based on the group velocity). For the data gathered in the wave flume the next $30 \mathrm{~s}$ of the time series is used for analysis, whereas for the Ocean Basin data a maximum of $60 \mathrm{~s}$ is considered unless the time $t=90 \mathrm{~s}$ is exceeded. In both phases, the time series' are further truncated to ensure an integer number of waves are in the record, and experimental noise was filtered out using a low pass Butterworth digital and analog filter [9]. The mean values are simply calculated as the mean of these filtered and truncated time series'. To calculate the cyclic amplitudes, a Fast Fourier Transform (FFT) approach is used based on the first three odd harmonics.

\section{Mean Performance and Loading}

\subsection{Mean Turbine Loading}

\subsubsection{Isolated Conditions}

Figure 9 presents the thrust coefficient $(\bullet)$ obtained in the 1:33 scale flume tests (Section 2.1; ID 4 in Table 1 ) as a function of porosity, compared with data from previous studies for wind $[43,35,39,2]$ (as reported by Lignarolo et al. [30]), and tidal [36] applications. The gradient of the trend in the present results $(\cdots \cdots)$ is larger than that observed in previous wind applications $(---)$, and although the magnitude is slightly greater, it is close to the upper limits of the scatter seen in the wind data. This increased

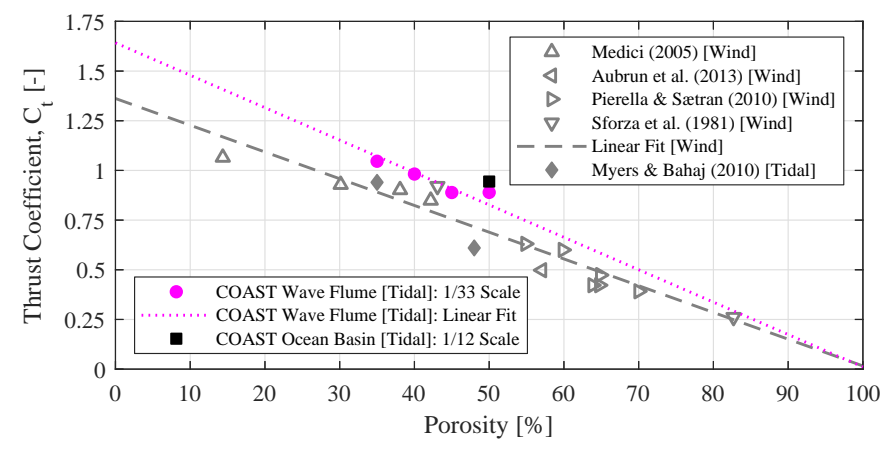

Figure 9: Measured thrust in the 1:33 scale wave flume $(\bullet)$ and 1:12 scale Ocean Basin ( $\boldsymbol{\square})$ tests as a function of porosity, compared with previously stated values for wind $(\diamond)$ and tidal $(\diamond)$ applications. Adapted from Lignarolo et al. [30].

magnitude could be due to a combination of blockage and the presence of the free surface, and it is thought that the porosity-thrust coefficient relationship is similar for both wind and tidal applications. The 1:12 scale disc used in the Ocean Basin tests was designed with a porosity of $50 \%$, giving an anticipated thrust coefficient of $C_{t}=0.89$ based on the 1:33 flume tests (Figure 9). However, the 1:12 scale disc was tested in the Ocean Basin (ID 11 in Table 1) and found to have a higher $C_{t}$ than expected $(0.94$, $\mathbf{\text { in Fig- }}$ ure 7) which was deemed acceptable but the reason for the increase has yet to be discovered.

\subsubsection{Entire MTG System}

Figure 10a presents the mean thrust on the turbine models when fixed in different current-only conditions. Both cases with an isolated turbine ( $\boldsymbol{\square})$ and integrated into the MTG system (o) are presented (ID's 11 and 15 respectively, in Table 1). The results imply that the load on (and hence power generated by) the turbine is greater when integrated into the MTG system. Curve fitting based on momentum theory [8] implies that the integrated turbine is characterised by a representative thrust coefficient of $C_{t}=1.047$; an $11 \%$ increase in thrust compared with the isolated turbine case. This is assumed to be due to a combination of a increase in local flow speed caused by channelling of the flow between the turbine model and the platform's hulls. This effect was not considered during the concept design and therefore these results suggest there is a possible optimisation opportunity to exploit.

Figure $10 \mathrm{~b}$ shows the mean vertical position of the $\mathrm{CoE}$ $\left(Z_{\text {coe }}\right)$ acting on the turbine model in current-only flow conditions, both in a fixed, isolated configuration (ם; ID 11 in Table 1) and loaded into the fixed MTG model (o; ID 15 in Table 1). Theoretically, one would expect that if there is negligible vertical velocity gradient, then $Z_{\text {coe }}$ should correspond with the centre of the disc in current-only conditions, and consequently no mean bending moment applied to the turbine model. However, in the present work the $Z_{\text {coe }}$ is generally observed to be very slightly above the centre of the disc $\left(0 \leq Z_{\text {coe }} \leq 0.02 R\right)$ when the turbine 

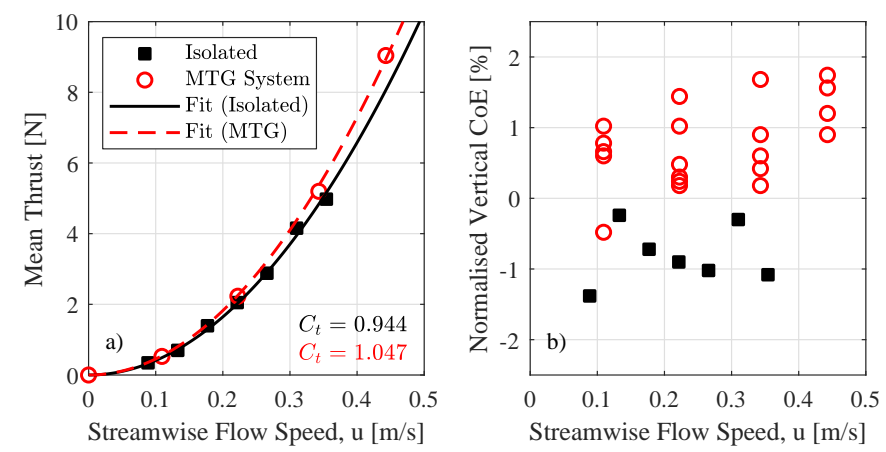

Figure 10: Comparison of the turbine thrust curve (a); and mean vertical centre of effort normalised by disc radius, $R$ (b), for the turbine model in isolated conditions ( $\mathbf{\square})$, and as part of the full MTG system (o) in the fixed configuration.

is loaded into the full MTG system. This is inconsistent with the observations for the isolated turbine ( $\mathbf{a}$ in Figure $10 \mathrm{~b})$ which show a $Z_{\text {coe }}$ slightly below the centre of the disc $\left(-0.02 R \leq Z_{\text {coe }} \leq 0\right)$, consistent with a small velocity gradient across the disc. It is worth noting that the observed $Z_{\text {coe }}$ values are small, and hence could be partially influenced by experimental errors such as slight misalignments in the laboratory setup. However, the change in $Z_{\text {coe }}$ between the isolated and loaded MTG cases is interesting since it is consistent with the structure channelling flow onto the top section of the turbine model; and/or an increase in platform pitch angle caused by the increased current speed [29]. This would potentially lead to both an increase in the total load on the turbine (as seen in Figure 10a) and a raise in $Z_{\text {coe }}$; and, although the magnitude is not altered in the present case due to the change in direction of $Z_{\text {coe }}$, under different circumstances (such as an alternative structure design or changes in flow conditions) this could lead to a relatively large mean bending moment on the turbine. The change in $Z_{c o e}$ highlights an opportunity to tune the structure design so that the channelled flow minimises the bending moment and/or increases the power output of the device. This creates a multi-objective optimisation problem (likely based on LCOE), which could potentially be aided by a high-fidelity numerical tool capable of capturing and characterising the complex flow around the structure [6].

Figure 11a shows the mean thrust on the turbine model loaded in the MTG system in wave-current (markers) and current-only (- - ) conditions; both fixed (ID's 15-17 in Table 1) and moored (ID's 21-23 in Table 1) cases are presented. The results show that in wave-current conditions, the observed mean loads are similar to the corresponding current-only cases, although there is a slight increase at low frequencies, possibly due to Stokes Drift [33] and/or alterations in the particle trajectories due to a change to the intermediate water depth regime. However, this could be explained as merely experimental noise as there is some scatter in the data, thought to be due to the incident flow turbulence level that was observed to increase with flow
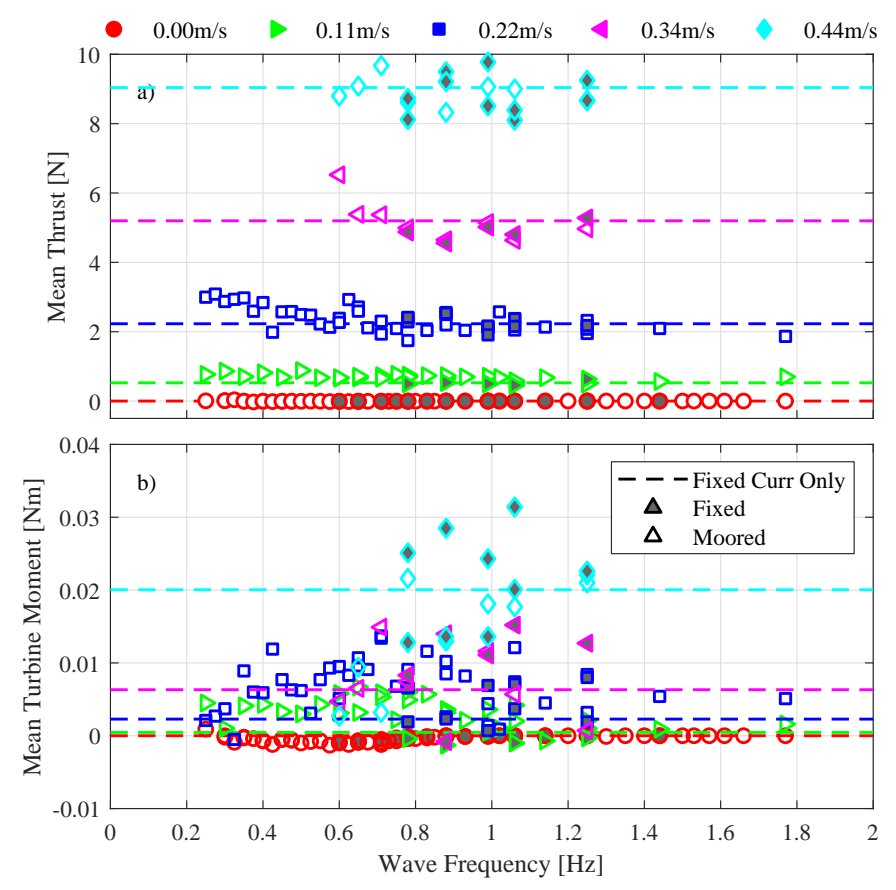

Figure 11: Mean thrust (a) and bending moment (b) on the turbine as a function of wave frequency for the fixed $(\Delta)$ and moored $(\Delta)$ configurations. A range of wave-current conditions are compared with the mean current-only load in the fixed configuration $(---)$, where the markers/colours represent the different current speeds: $0.00 \mathrm{~m} / \mathrm{s}(\bullet), 0.11 \mathrm{~m} / \mathrm{s}(\bullet), 0.22 \mathrm{~m} / \mathrm{s}(\boldsymbol{\bullet}), 0.34 \mathrm{~m} / \mathrm{s}(\triangleleft), 0.44 \mathrm{~m} / \mathrm{s}(\diamond)$.

speed. The similarity of the wave-current and current-only observations indicates that waves do not substantially alter the mean power output of the device, which is consistent with previous research $[18,23]$. Furthermore, Figure 11a shows very similar mean loads are recorded for both fixed and moored cases implying that wave-induced motion also has negligible effects on the mean thrust/mean power output. The consequences of these observations are that a simplified model, such as a linear superposition of waves and currents, is expected to be an adequate method for predicting the mean load and power output of the system.

Figure 11b shows the mean bending moment on the turbine model loaded in the MTG system in wave-current (markers) and current-only (-- -) conditions; both fixed (ID's 15-17 in Table 1) and moored (ID's 21-23 in Table 1) cases are presented. In contrast to the mean thrust, the mean bending moment does show some differences between the current-only and wave-current results. The mean bending moments (and $Z_{\text {coe }}$ ) in the wave-current cases are generally greater than seen in the corresponding current-only data, which could imply it is caused by wavecurrent interaction, especially since the wave-only results (o) show close to zero bending moment, as expected. The direction of the bending moment in wave-current conditions (i.e. positive $Z_{\text {coe }}$ ) is consistent with the observations in current-only, and the motion of the device does not seem to influence the results substantially. 

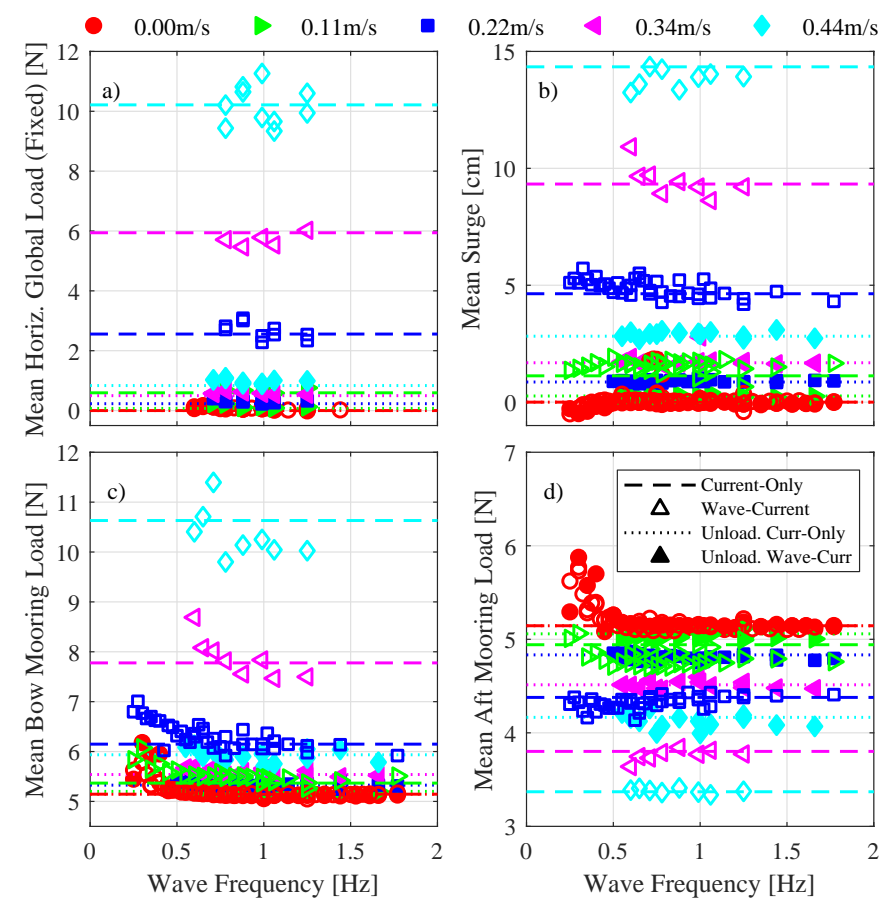

Figure 12: Mean horizontal streamwise global load in the fixed configuration (a), surge position (b), bow mooring load (c), and aft mooring load (d) in the moored configuration as a function of wave frequency. A range of wave-current conditions are compared with the mean current-only values in the fixed configuration (-- ), where the markers/colours represent the different current speeds: $0.00 \mathrm{~m} / \mathrm{s}(\bullet)$, $0.11 \mathrm{~m} / \mathrm{s}(\triangleright), 0.22 \mathrm{~m} / \mathrm{s}(\boldsymbol{\bullet}), 0.34 \mathrm{~m} / \mathrm{s}(\triangleleft), 0.44 \mathrm{~m} / \mathrm{s}(\triangleleft)$.

\subsection{Mean Global and Mooring Loading}

Figure $12 \mathrm{a}$ shows the mean horizontal ( $x$-component) load on the entire structure when fixed in place and subject to wave-current conditions; both the unloaded $(\boldsymbol{\Delta}$; ID's $13-14$ in Table 1 ) and loaded ( $\Delta$; ID's $16-17$ in Table 1) cases are presented. Also presented are the mean horizontal global loads for both the fixed loaded (-- -) and unloaded $(\cdots .$.$) ) platform in current-only conditions$ (ID's 12 and 15, respectively in Table 1). It is observed that the mean horizontal global loads are substantially increased in the loaded configuration (---; ID's 15-17 in Table 1) compared with the unloaded platform (.....; ID's 12-14 in Table 1), and that the relative difference increases with flow speed. This indicates that the drag on the turbine dominates the mean horizontal load on the system, which is to be expected since the turbine model considerably increases the underwater surface area of the system. Comparing the mean horizontal global loads (- - in Figure 12a) with the mean turbine thrust in currentonly conditions (-- - in Figure 11a), it can be observed that the magnitudes are similar. For instance in the highest flow speed cases considered here $(u=0.44 \mathrm{~m} / \mathrm{s},---)$, the load on the turbine is $9.04 \mathrm{~N}$ and the global horizontal load is $10.21 \mathrm{~N}$, implying that the turbine contributes $89 \%$ of the global load. The increased horizontal global load leads to an increase in the mean (equilibrium) surge position (Figure 12b), and consequently the loads in the bow (Figure 12c) and aft (Figure 12d) moorings increase and decrease, respectively.

In wave-current conditions the mean global loads $(\Delta$ in Figure 12a) do not deviate substantially from those obtained in current-only conditions. This is generally also observed in the mean surge, bow, and aft moorings (Figure $12 \mathrm{~b}-\mathrm{d})$, suggesting that waves do not influence the mean characteristics of the system in operational conditions, and that they can be predicted based on the current speed alone. However, at low frequencies $(f \leq 0.5 \mathrm{~Hz})$ there are some slight differences in the mean surge position and mooring loads that could be due to Stokes Drift, or nonlinear effects introduced from wave-current interaction. Interestingly, for the wave-only cases the mean surge is reduced, while both moorings show increased loads which could be due to an increase in another degree of freedom; small levels of yaw were observed in the low-frequency cases but the increase could be due to a combination of other factors such as tank effects.

\section{Device Motion and Cyclic Loading}

\subsection{Motion Response}

Figure 13 presents the surge (a), heave (c) and pitch (e) RAO curves for the unloaded (•) and loaded (o) MTG device in wave-only conditions (ID's 19 and 22, respectively, in Table 1). The wave height used for the normalisation (Section 2.2.2) is that recorded in the calibration experiments where available, otherwise the in-situ data is used, both from location W1 (Figure 4b). Also shown is a numerical prediction $(-x)$ obtained using the panel method code ANSYS AQWA [1] based on the wave-excitation of the unloaded structure only, i.e. no currents or moorings are included. The physical data for the unloaded platform is shown to agree very well with the numerical prediction, implying that the response of the platform (without the turbine) can be predicted by linear potential theory and is a good basis on which to assess the effects of currents and turbine load. There are, however, some small discrepancies in the numerical solution such as the magnitude and bandwidth of the peak in pitch, which may be caused by the absence of the moorings in the numerical model. In general, it is interesting that the lack of moorings in the numerical model does not have a larger effect on the solution, and it implies that the response in wave-only conditions is either not overly sensitive to the mooring system or that the present system used is particularly compliant. In cases with the turbine model loaded (o), the response of the system does not deviate substantially from the unloaded response, indicating that the platform's motion is not sensitive to the presence and additional mass of the turbine for this particular mooring arrangement in waveonly conditions.

Figure 13 also shows the surge (b), heave (d) and pitch (f) RAO curves for the unloaded (•) and loaded (o) MTG device in wave-current conditions (ID's 20 and 23, respectively, in Table 1). The surge response is observed to be 


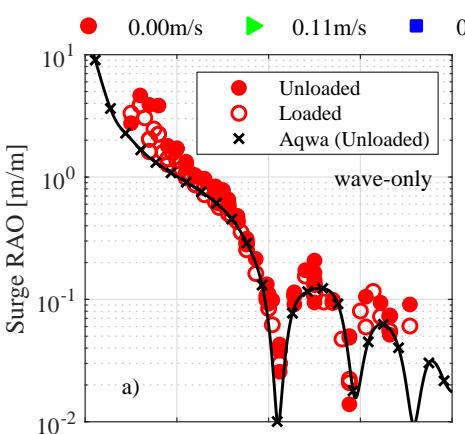

$0.22 \mathrm{~m} / \mathrm{s} \triangleleft 0.34 \mathrm{~m} / \mathrm{s} \diamond 0.44 \mathrm{~m} / \mathrm{s}$
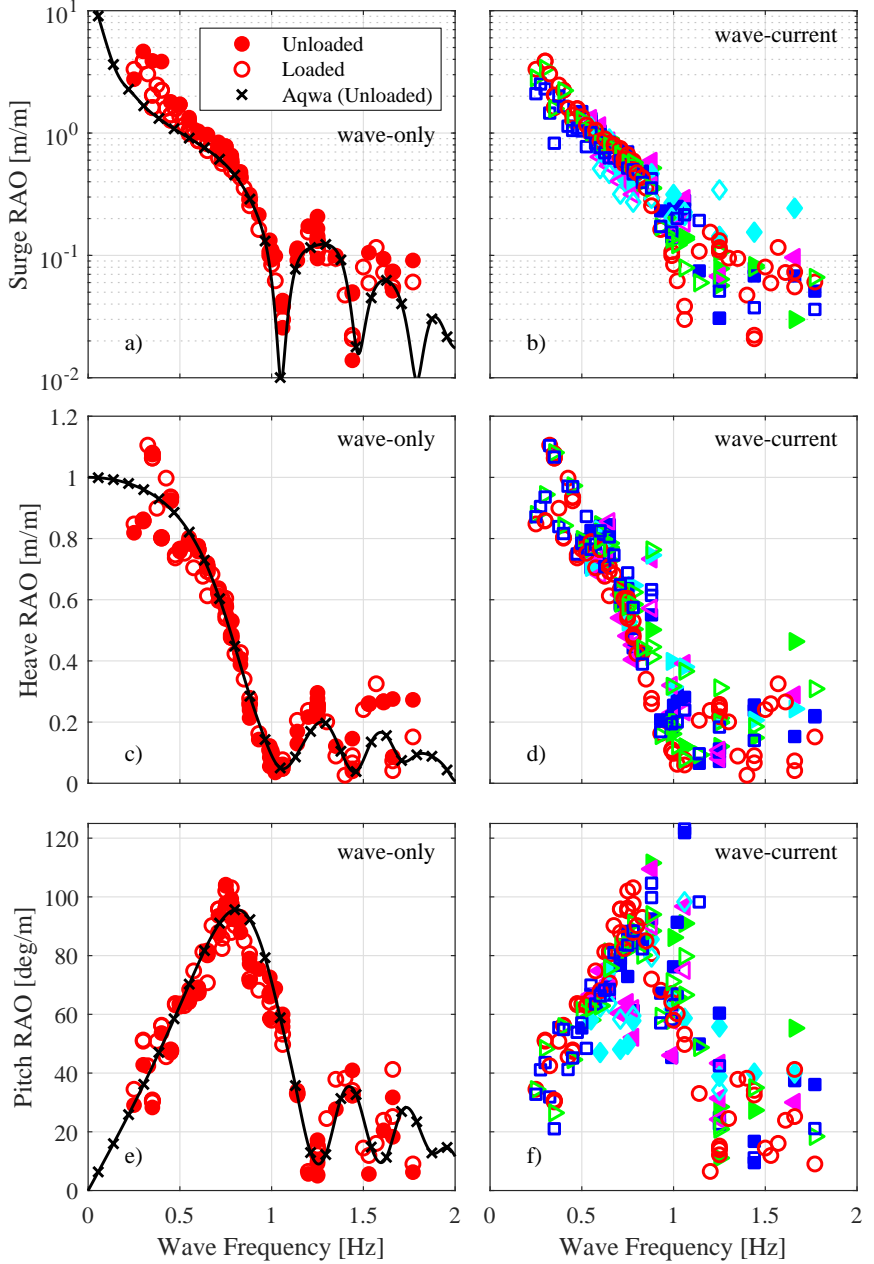

Figure 13: Comparison of the RAO curves for the loaded $(\Delta)$ and unloaded ( $\boldsymbol{\Delta})$ MTG model in wave-only (a,c,e) and wave-current (b,d,f) conditions: surge $(\mathrm{a}, \mathrm{b})$, heave $(\mathrm{c}, \mathrm{d})$ and pitch $(\mathrm{e}, \mathrm{f})$. A wave-only numerical solution $(-x)$ is also shown. The markers/colours indicate current speed: $0.00 \mathrm{~m} / \mathrm{s}(\bullet), 0.11 \mathrm{~m} / \mathrm{s}(\bullet), 0.22 \mathrm{~m} / \mathrm{s}(\boldsymbol{\bullet}), 0.34 \mathrm{~m} / \mathrm{s}(\triangleleft)$, $0.44 \mathrm{~m} / \mathrm{s}(\diamond)$.

largely unaffected by the current speed (Figure 13b), except for a slight reduction with flow speed at low wave frequencies. Furthermore, the surge response does not differ substantially between the loaded and unloaded platform. This is interesting since the mean surge was observed (Section 3.2) to increase considerably in wave-current conditions when the turbine was loaded (compared with the unloaded device), and implies that the cyclic surge response is not overly dependent on the presence of the turbine, nor particularly sensitive to the mean offset or associated increase (decrease) in bow (aft) mooring loads. The heave and pitch responses also show very little changes with flow speed (Figure 13d,f). There is a slight increase in the natural frequency with current speed, but there is also relatively large scatter in the results for these faster flow cases (likely due to turbulent fluctuations). A slight reduction in pitch response (Figure 13f) is observed near the natural frequency for the highest two flow speeds $(\triangleleft, \diamond)$, but since
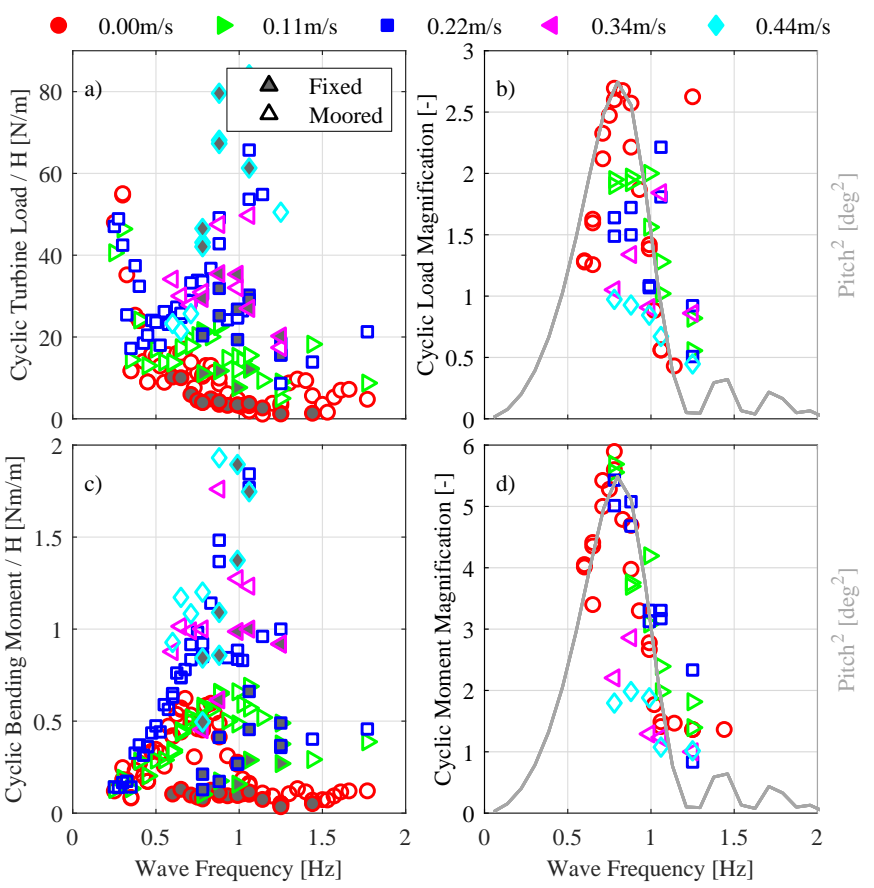

Figure 14: Cyclic amplitude per unit wave height of the loading (a) and bending moment (c) on the turbine for the loaded MTG platform in wave-current conditions, and both the fixed $(\Delta)$ and moored $(\Delta)$ configurations. Also shown is the magnification factor of the cyclic amplitude of load (b) and bending moment (d) for the moored platform relative to the fixed case, with the pitch RAO response squared in wave-only conditions overlaid for comparison. The markers/colours represent the different current speeds: $0.00 \mathrm{~m} / \mathrm{s}(\bullet)$, $0.11 \mathrm{~m} / \mathrm{s}(\triangleright), 0.22 \mathrm{~m} / \mathrm{s}(\boldsymbol{\nabla}), 0.34 \mathrm{~m} / \mathrm{s}(\triangleleft), 0.44 \mathrm{~m} / \mathrm{s}(\triangleleft)$.

the unloaded cases $(\triangleleft, \diamond)$ also show a similar response, it must be an effect of the wave-current interaction (or tank effects) rather than the turbine model itself. The lack of substantial deviations implies that in operational conditions a simplified model, such as a linear superposition of wave and current components, will provide a suitable prediction for the behaviour of the MTG device.

Before the physical campaign, it was hypothesised that the turbine model would introduce a 'lever-arm' type damping to the pitch of the system, and potentially increase the surge oscillations. This has not been observed here, and this has both positive and negative implications for a developer. On one hand, the high pitch motion will accelerate fatigue on the device (Section 4.2), reducing the lifespan of the components, increasing costs for maintenance and negatively impacting the cost-effectiveness of the device. On the other hand, the positives are that the mooring system, and any potential operations such as turbine installation and maintenance which require an understanding of device motion, can be designed for a single cyclic response that is not dependent on the addition of the turbine or increased flow speed. It is worth noting that in the MTG design the turbine is positioned in the centre of the platform (Figures 1 and 5), and hence for alternative turbine positions different behaviour might be observed. 


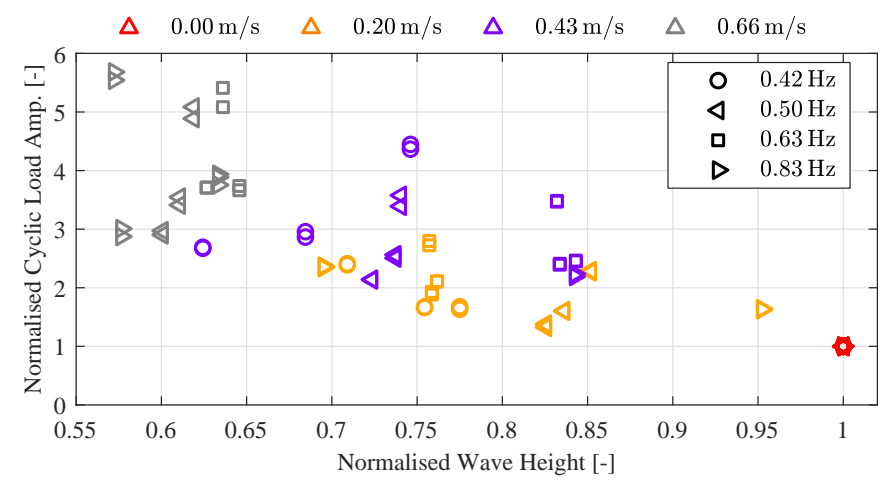

Figure 15: Cyclic amplitude of turbine load observed in the turbineonly wave flume tests in wave-current conditions, as a function of wave height. Frequencies are distinguished by marker ( $f=0.42 \mathrm{~Hz}$; $\triangleleft 0.50 \mathrm{~Hz} ; \square 0.63 \mathrm{~Hz} ; \triangleright 0.83 \mathrm{~Hz})$ and current by colour $(\Delta u=$ $0.00 \mathrm{~m} / \mathrm{s} ; \triangle 0.20 \mathrm{~m} / \mathrm{s} ; \triangle 0.43 \mathrm{~m} / \mathrm{s} ; \triangle 0.66 \mathrm{~m} / \mathrm{s})$. Both the cyclic load and wave height are normalised by the corresponding value observed in wave-only conditions.

\subsection{Turbine Cyclic Loading}

Figures 14a and 14c show the cyclic amplitudes (per unit wave height) of loading on the turbine and bending moment on the turbine, respectively, in wave-current conditions for the fixed ( $\Delta$; ID's $16-17$ in Table 1 ) and moored $(\Delta$; ID's 22-23 in Table 1 ) MTG device. The cyclic amplitude of the turbine load and bending moment are observed to increase with flow speed for both the fixed and moored system. Since the following currents reduce the amplitude of the wave (see Figure 8), the observed increase is counterintuitive and implies that a linear superposition of waves and currents will not provide an accurate prediction for the cyclic amplitude of turbine load. Although it is possible that these effects are modified by the flow around the structure, an increase in the the cyclic amplitude of turbine load (and a reduction in wave height) was also observed in the wave flume tests (Figure 15) using the isolated 1:25 scale disc (see Section 2.1; ID's 6-7 in Table 1), implying that the hydrodynamic interaction with the platform is not the cause. Combining this with the fact that this observation was made in both fixed and moored configurations, it must be due to a characteristic inherent in the hydrodynamics, i.e. wave-current interaction effects are important and, hence, a linear superposition of waves and currents is not valid, which is consistent with conclusions from previous hydrodynamic studies [24, 47].

Figures $14 \mathrm{~b}$ and $14 \mathrm{~d}$ show the magnification factor for the cyclic amplitude of load and bending moment on the turbine, respectively, in moored cases ( $\Delta$ in Figure $14 \mathrm{a}$; ID's 22-23 in Table 1), relative to that observed in the fixed tests ( $\Delta$ in Figure 14a; ID's $16-17$ in Table 1 ). It appears that the motion of the device in the floating cases substantially increases the amplitude of the cyclic loading, i.e. magnification greater than 1, particularly at lower flow speeds. The cyclic bending moment is also seen to be highly magnified, and this amplification does not reduce with current speed (except at high flow speeds). Since
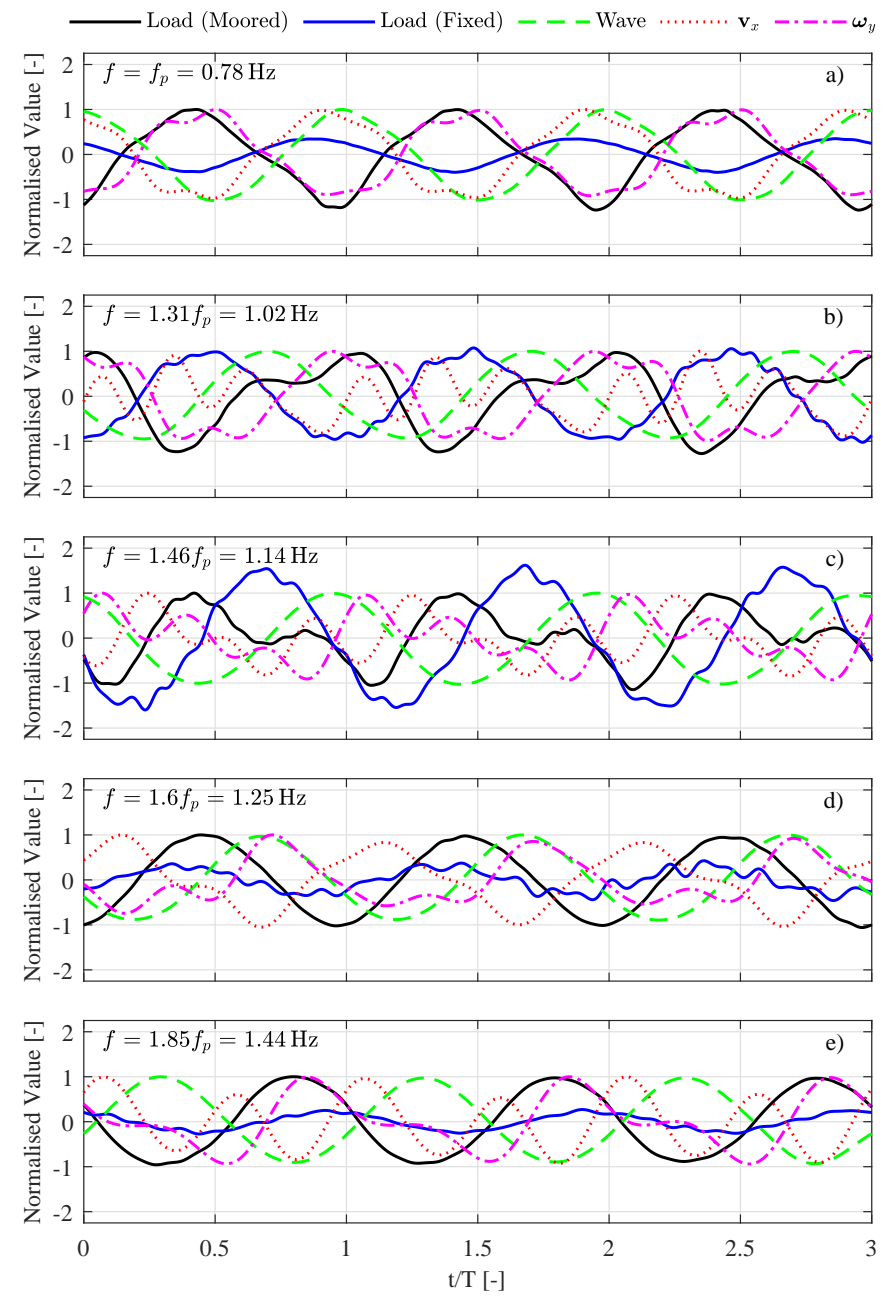

Figure 16: Comparison of normalised time series' of the turbine load in the moored (- - and fixed ( - ) configuration along with the wave $(---)$, horizontal platform velocity $(\cdots .$.$) ) and pitch velocity$ of the platform (i.e. angular velocity about the $y$-axis; - - - ), for wave frequencies $f=f_{p}=0.78 \mathrm{~Hz}(\mathrm{a}), 1.02 \mathrm{~Hz}$ (b), $1.06 \mathrm{~Hz}$ (c), $1.14 \mathrm{~Hz}$ (d), and $1.25 \mathrm{~Hz}(\mathrm{e})$, where $f_{p}$ is the pitch peak frequency. Each variable is normalised by its maximum value, except for the fixed load which is normalised by the maximum moored load.

this is inconsistent with the trend in cyclic load, it must be caused by either a change in the position of the $\mathrm{CoE}$ or the relative phase between the position of $\mathrm{CoE}$ and the cyclic load.

Figures 14b and 14d also have the pitch RAO squared (since thrust is proportional to velocity squared) response overlaid (- - for comparison. The magnification factor for both cyclic load and bending moment appear to have a strong correlation with the pitch squared response, particularly in the wave-only cases, indicating that the response is sensitive to the pitch velocity of the system. To investigate this in more detail, Figure 16a presents a comparison of the times series' at the pitch natural frequency $\left(f_{p}=0.78 \mathrm{~Hz}\right)$ in wave-only conditions for: the turbine load in fixed $(-)$ and moored (-) configurations; free surface elevation $(---)$ at W3 (in-line with the turbine model, see Figure 4b); and the pitch velocity of the plat- 
form about the $y$-axis, $\boldsymbol{\omega}_{y}(-\cdot-)$ and linear velocity along the $x$-axis, $\mathbf{v}_{x}(\cdots \cdots)$, calculated as the time derivative of pitch and surge, respectively. Each variable has been normalised by its maximum value in the presented three wave periods, except for the load in the fixed case which is normalised by the maximum load in the moored case (to highlight the magnification of the signal). The pitch velocity of the platform is in anti-phase compared with the wave profile (and hence horizontal velocity) at this wave frequency, and therefore is acting against the flow direction increasing the apparent flow speed over the turbine. By definition, the peak frequency will induce the largest pitch response, and hence the greatest platform pitch velocity will be observed (and amplified by a 'lever-arm' effect) at this wave frequency (as seen in Figure 14a). Combining the large magnitude with the phase, this causes the substantial magnification factor that is seen at this wave frequency in Figure 14b, and is consistent with the results of previous numerical modelling of a generic floating system [6]. Theoretically, one would expect that the linear velocity due to the surge motion would also alter the apparent flow speed over the turbine. This has been observed in previous numerical modelling studies of floating tidal energy concepts with both horizontal-axis [50] and vertical-axis [44] turbines, which showed that both the amplitude and frequency of the surge motion affect the cyclic loading and power output of a turbine. In the present experimental results, the surge velocity is in phase with the wave near the peak pitch frequency, which will in theory reduce the apparent flow. This mitigates the effect of pitch to some extent, but the high correlation between the turbine loading in the moored configuration with the pitch velocity of the platform, along with the high magnification factor, indicates that pitch is dominant at this frequency. As the wave frequency moves away from the pitch resonance frequency, the phase of the pitch and surge changes to be closer to that of the wave, reducing the contribution, to considerably less than observed in the fixed configuration in some cases (Figure 16b-c). Although the magnitude of the cyclic load reduces at these frequencies, the signal becomes much more complex (e.g. higher frequency components are observed in Figures 16b-c, causing a double peak), which will both complicate power delivery and increase fatigue on the system. At some frequencies, such as $f=1.25 \mathrm{~Hz}$ (Figure 16d), the pitch velocity of the platform is in phase with the wave, theoretically reducing the apparent flow speed over the turbine, and yet the magnification factor is relatively large. This is due to the small magnitude of pitch (Figure 13e) at this wave frequency, and a combination of a spike in surge response (Figure 13a) and the surge being out of phase with the wave. As the wave frequency approaches the second harmonic of pitch (Figure 16e), the pitch velocity of the platform is once again in anti-phase compared with the wave and a large magnification factor is observed.

The coupling between the cyclic amplitude of turbine load and the motion of the platform is clearly highly de-
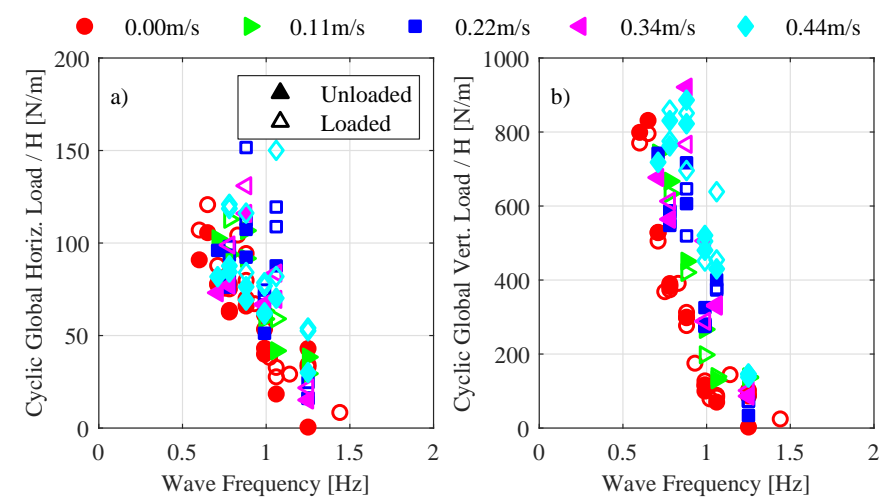

Figure 17: Cyclic amplitude per unit wave height of streamwise horizontal (a) and vertical (b) global load, for the fixed MTG platform in wave-current conditions, both loaded (०) and unloaded $(\bullet)$. The markers/colours represent the different current speeds: $0.00 \mathrm{~m} / \mathrm{s}(\bullet)$, $0.11 \mathrm{~m} / \mathrm{s}(\triangleright), 0.22 \mathrm{~m} / \mathrm{s}(\square), 0.34 \mathrm{~m} / \mathrm{s}(\triangleleft), 0.44 \mathrm{~m} / \mathrm{s}(\triangleleft)$.

pendent on wave frequency in wave-only conditions, and sensitive to not only the magnitude of the motion but also the phase relative to other degrees of freedom and the wave. Although in more complex wave-current flows it is likely that the current will often dominate, there may be circumstances where the coupling between the cyclic loading and the platform motion is substantial, and dependent on a more complicated phase relationship and interaction between the pitch, waves and currents. Furthermore, the amplitude of the cyclic bending moment is further complicated by the phase of the position of the CoE. Therefore, it is essential that the relationship between CoE, cyclic loading and bending moment is established in wave-only conditions in order to provide a basis to consider the addition of currents. This highlights the value of physical data obtained using an incremental approach, such as the one presented here, since it can both help to establish a fundamental understanding and identify any further modelling (physical or numerical) that may be required in the future to fully evaluate this in wave-current conditions.

\subsubsection{Global and Mooring Cyclic Loading}

Figure 17 presents the cyclic amplitude (per unit wave height) of streamwise horizontal (a) and vertical (b) components of the global load, for the fixed MTG structure in wave-current conditions, both loaded (o; ID's 13-14 in Table 1) and unloaded (•; ID's 16-17 in Table 1 ). The cyclic amplitude of global horizontal load is slightly increased with the turbine installed, compared to the platform alone. Conversely, the cyclic amplitude of the vertical component is largely unaffected by the introduction of the turbine to the system, as expected since it is aligned parallel to the $z$-axis (Figure 5). The vertical component does, however, appear to be more sensitive to wave-current interaction effects, showing a substantial increase with current speed (and a possible shift to a higher natural frequency) that is not observed in the horizontal component. The small magnitude of the increase in the cyclic amplitude of global 

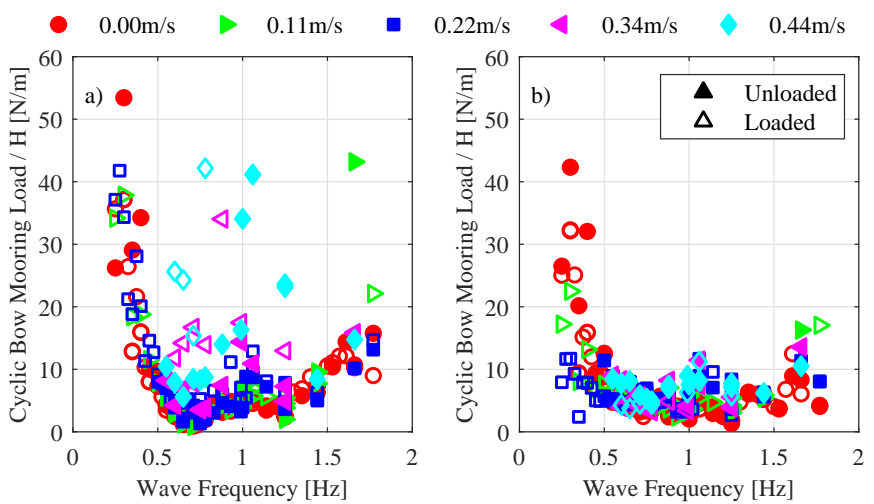

Figure 18: Cyclic amplitude per unit wave height of bow (a) and aft (b) mooring loads, for the moored MTG platform in wave-current conditions, both loaded (o) and unloaded $(\bullet)$. The markers/colours represent the different current speeds: $0.00 \mathrm{~m} / \mathrm{s}(\bullet), 0.11 \mathrm{~m} / \mathrm{s}(\bullet)$, $0.22 \mathrm{~m} / \mathrm{s}(\square), 0.34 \mathrm{~m} / \mathrm{s}(\triangleleft), 0.44 \mathrm{~m} / \mathrm{s}(\triangleleft)$.

horizontal load is surprising when one considers the large increase in surface area (and hence drag) due to the turbine, and suggests that the oscillating component, i.e. the waves, is small compared to the mean.

Figure 18 shows the cyclic amplitude (per unit wave height) of bow (a) and aft (b) mooring load, for the moored MTG structure in wave-current conditions, both loaded (o; ID's 18-19 in Table 1) and unloaded (•; ID's 22-23 in Table 1). Similar to the observations for the cyclic global load, the cyclic amplitude of the mooring loads are not overly sensitive to the presence of the turbine, reinforcing that the oscillating component is small in comparison to the mean. The flow speed, however, does have some effects on the mooring load. Firstly, at low frequencies $(f \leq 0.5 \mathrm{~Hz})$ there is a reduction in the cyclic amplitude in the aft mooring load (with no clear changes observed in the bow mooring). Secondly, at mid-frequencies centred around $f=1 \mathrm{~Hz}$, an increase in both the cyclic amplitude of the bow and aft mooring load is observed, with more obvious deviations (and scatter) in the former. This increased cyclic amplitude in the mooring loads corresponds with a peak in the roll RAO curve (generated either parametrically or by slight misalignments in the experimental setup), implying that they are related. This observation highlights one crucial area of future research: the sensitivity of the device behaviour to wave direction needs to be characterised, since oblique waves could have considerable impact on lateral loads, turbine/mooring performance and fatigue.

\section{Discussion}

The analysis of the mean characteristics of the model shows that the presence of the free surface does not substantially alter the mean power implying that, in the long term, the energy generated by the system can be evaluated based on current speeds alone. Furthermore, although the increased drag from the turbine does lead to an offset in mean surge equilibrium position, and consequently an increase (decrease) in mean load in the bow (aft) mooring, the wave-current cases did not generally show any substantial deviations from the current-only tests. Again this suggests that mean loads can be calculated based on analysis in current-only conditions.

The cyclic mooring and global loads on the system are generally observed to be independent of current speed and can be characterised by the observed wave alone: i.e. the cyclic load amplitudes are similar in wave-only and wavecurrent conditions, hence simplifying any modelling processes used to design the moorings. There are, however, some potential concerns for developers if effects from waveinduced cyclic behaviour and motion of the system on the turbine are considered. Wave-current interaction effects have been shown here to lead to a substantial increase in the amplitude of the cyclic load on the turbine with current speed. Coupling this with a further increase due to the motion around the harmonics of the pitch natural frequency, this could potentially have serious implications for the quality of the power delivery, fatigue on the turbine, and consequently the lifespan of components, negatively impacting the LCOE. Therefore, to increase the lifespan of a tidal turbine, it could be beneficial to minimise the motion of the system or alter the pitch natural frequency according to the wave climate at the site. One method to mitigate platform motion would be to increase the stiffness of the mooring system to make it less compliant; however, this will lead to higher mooring loads and consequently an increase in cost and/or reduction in the lifespan of that component instead. Another possible option would be to position the turbines closer to the centre of rotation to minimise any lever-type effects. Alternatively it may be possible to position or control the turbines such that the additional mass, thrust and moment counteract the motion of the system; however this would likely lead to more complicated motion, and increased fatigue on the moorings. Further work is required to determine the best solution, which is expected to be a compromise.

With the exception of the cyclic amplitude of the load and bending moment on the turbine, it seems that the present problem can be addressed through a linear superposition of waves and currents. This simplification is likely to be welcomed by developers since it implies that the long-term power output and loads on the system in relatively calm (operational) conditions can be accurately determined using existing analytical and lower-fidelity numerical tools. However, there are a number of caveats that should be noted:

- Due to the design of the MTG concept, and the relatively shallow test conditions, the turbine is located at mid-water depth in this work. Previous hydrodynamic studies on wave-current flows have shown that a linear superposition of waves and currents does not capture the true flow velocities [24, 25, 47], and in the case of following in-line currents there is an in- 
crease in flow speed near the surface and reduction near the seabed [24]. However, there is a region at mid-water depth where the linear superposition does give good agreement, and this, coincidently, is close to where the turbine is situated in this work. Therefore, if the same device was deployed at a deeper site, the relative location of the turbine to the free surface would be smaller, and hence wave-current interaction effects would have a greater influence on the mean performance and loading on the turbine.

- The maximum flow speeds $(1.5 \mathrm{~m} / \mathrm{s}$ at full scale) and wave heights considered here are relatively low, and hence it is possible that further complexities are introduced for higher flow speeds and/or steeper waves due to effects such as increased Stokes Drift.

- In-line following currents have been considered in this study, which reduce the height of the wave, and hence the motion of the platform. Further work is required to consider oblique waves (including opposing currents that theoretically should amplify the wave height, and consequently the cyclic load amplitudes), that may cause lateral loading, as well as more extreme conditions for the purpose of survivability.

- Characteristics that relate to individual turbine design have been neglected here, such as cut-in and cut-out speeds which could potentially reduce the power output of the device.

- The flow over the turbine will be sensitive to the design of the platform. Therefore, although relatively small increases in mean loading on the turbine were observed in this study, optimisation work in the future could potentially lead to channelling of the flow over the turbine and hence a more substantial increase in load, power and bending moment.

A combination of these factors is likely to increase the complexity of the problem to an extent that the additional computational cost of a high-fidelity numerical code could be justified to provide complimentary data [6]. As well as being able to provide a large quantity of spatial data relating to the flow interaction with the device, these highfidelity numerical models would allow further exploration into the coupling between the individual components of the system through: isolation of components, including removal of parts which are only necessary for physical experiments (e.g. support structures in turbine-only); measurements can be taken non-intrusively, reducing the uncertainty due to the presence of the instruments; and considering alternative water depths with no physical limits due to scaling effects. However, these models do require validation, and the physical data presented here offers an opportunity to establish suitable benchmarks, and hence build the foundations for the further progression of the floating tidal energy sector.

\section{Conclusions}

This paper aims to improve our understanding of free surface and current flow interactions with floating tidal systems, and focuses on potential changes to the performance, behaviour and longevity using a laboratory scale model of an existing design that can be considered pseudogeneric. In the relatively benign flow conditions considered in this work, the present device concept generally shows behaviour consistent with a linear superposition of the waves and currents; where the currents characterise the mean components, and the waves the cyclic component. However, the amplitude of the cyclic loading (and consequently the amplitude of the cyclic power production) is increased due to the platform's motion, with particularly large changes observed around the harmonics of the pitch natural frequency. Combining this with a further increase in the amplitude of cyclic loading due to wave-current interaction, this potentially has serious implications for the quality of the power delivery and fatigue on the turbine. Further work, using physical or numerical modelling, is required in the future to parametrise this increase in cyclic load amplitude. A model which includes turbine rotational effects should be considered in a wider range of flow conditions to assess the effect of incident wave angles, higher flow speeds and wave steepness, with attention on the effects caused by the relative location of the turbine to the free surface.

\section{Data Availability}

Achieving wave-current conditions with high quality and fast flow speeds without reducing the scale of the device (and hence reducing the signal to noise ratio) is presently challenging in most wave basin facilities, and hence data for entire floating tidal systems is generally not readily available. Therefore, data from the present experiments is available through the Collaborative Computational Project in Wave Structure Interaction (CCP-WSI) [EP/M022382/1], which aims to bring together the community of researchers, data, code and expertise within the area of wave-structure interaction (https ://www . ccp-wsi . ac.uk). It is hoped that the availability of this data will provide a useful benchmark for validating numerical tools [6], and progress the future development of floating tidal devices.

\section{Acknowledgements}

The authors acknowledge that this work was funded as part of Innovate UK Project 103499 through the Energy Catalyst programme, with additional support from the Engineering and Physical Sciences Research Council (EPSRC) via the Partnership for Research in Marine Renewable Energy [EP/P026109/1], Supergen ORE Hub [EP/S000747/1] and CCP-WSI [EP/M022382]. 


\section{References}

[1] ANSYS, Inc., 2019. ANSYS Aqwa. website. https:// wWw . ansys.com/products/structures/ansys-aqwa accessed 1st March 2019.

[2] Aubrun, S., Loyer, S., Hancock, P., Hayden, P., 2013. Wind turbine wake properties: Comparison between a non-rotating simplified wind turbine model and a rotating model. J. Wind Eng. Ind. Aerodyn. 120, 1-8.

[3] Bahaj, A., Batten, W.M.J., McCann, G., 2007a. Experimental verifications of numerical predictions for the hydrodynamic performance of horizontal axis marine current turbines. Renewable Energy 32, 2479-2490.

[4] Bahaj, A., Myers, L., 2003. Fundamentals applicable to the utilisation of marine current turbines for energy production. Renewable Energy 28, 2205-2211.

[5] Bahaj, A., Myers, L., Thomson, M., Jorge, N., 2007b. Characterising the wake of horizontal axis marine current turbines, in: Proceedings of the 7th European Wave and Tidal Energy Conference, Porto, Portugal. p. 9.

[6] Brown, S., Ransley, E., Xie, N., Greaves, D., Johanning, L., Guerrini, E., 2019. Validation of a coupled CFD model for evaluating floating tidal systems, in: Proceedings of the 29th International Ocean and Polar Engineering Conference, Hawaii, USA. pp. 2800-2807.

[7] Bryden, I.G., Naik, S., Fraenkel, P., Bullen, C.R., 1998. Matching tidal current plants to local flow conditions. Energy 23, 699-709.

[8] Burton, T., Jenkins, N., Sharpe, D., Bossanyi, E., 2001. Wind Energy Handbook. 2 ed., John Wiley \& Sons, Ltd.

[9] Butterworth, S., 1930. On the theory of filter amplifiers. Experimental Wireless \& the Wireless Engineer 7, 536-541.

[10] Chen, L., Lam, W.H., 2015. A review of survivability and remedial actions of tidal current turbines. Renewable and Sustainable Energy Reviews 43, 891-900.

[11] Dalton, G., Allan, G., Beaumont, N., Georgakaki, A., Hacking, N., Hooper, T., et al., 2015. Economic and socio-economic assessment methods for ocean renewable energy: Public and private perspectives. Renewable and Sustainable Energy Reviews 45, 850-878.

[12] Day, A., Babarit, A., Fontaine, A., He, Y.P., Kraskowski, M., Murai, M., et al., 2015. Hydrodynamic modelling of marine renewable energy devices: A state of the art review. Ocean Engineering 108, 46-69.

[13] Devine-Wright, P., 2011. Enhancing local distinctiveness fosters public acceptance of tidal energy: A UK case study. Energy Policy 39, 83-93.

[14] El Tawil, T., Charpentier, J.F., Benbouzid, M., 2017. Tidal energy site characterizarion for marine turbine optimal installation: Case of the Ouessant Island in France. International Journal of Marine Energy 18, 57-64.

[15] Fernandez-Rodriguez, E., Stallard, T., Stansby, P., 2014. Experimental study of extreme thrust on a tidal stream rotor due to turbulent flow and with opposing waves. Journal of Fluids and Structures 51, 354-361.

[16] Galloway, P., Myers, L., Bahaj, A., 2010. Studies of a scale tidal turbine in close proximity to waves, in: Proceedings of the 3rd International Conference on Ocean Energy, Bilbao, Spain. pp. $1-6$.

[17] Galloway, P.W., Myers, L.E., Bahaj, A.S., 2014. Quantifying wave and yaw effects on a scale tidal stream turbine. Renewable Energy 63, 297-307.

[18] Gaurier, B., Davies, P., Deuff, A., Germain, G., 2013. Flume tank characterization of marine current turbine blade behaviour under current and wave loading. Renewable Energy 59, 1-12.

[19] Grant, W.D., Madsen, O.S., 1979. Combined wave and current interaction with a rough bottom. Journal of Geophysical Research 84, 1797-1808.

[20] Greaves, D., Iglesias, G., 2018. Wave and Tidal Energy. John Wiley \& Sons Ltd.

[21] Guney, M.S., Tepe, Y., 2017. Classification and assessment of energy storage systems. Renewable and Sustainable Energy Reviews 75, 1187-1197.

[22] Jeffcoate, P., McDowell, J., 2017. Performance of PLAT-I, a floating tidal energy platform for inshore applications, pp. 1-8.

[23] de Jesus Henriques, T.A., Tedds, S.C., Botsari, A., Najafian, G., Hedges, T.S., Sutcliffe, C.J., et al., 2014. The effects of wavecurrent interaction on the performance of a model horizontal axis tidal turbine. International Journal of Marine Energy 8, 17-35.

[24] Kemp, P.H., Simons, R.R., 1982. The interaction between waves and a turbulent current: waves propagating with the current. Journal of Fluid Mechanics 116, 227-250.

[25] Kemp, P.H., Simons, R.R., 1983. The interaction between waves and a turbulent current: waves propagating against the current. Journal of Fluid Mechanics 130, 73-89.

[26] Lazakis, I., Turan, O., Rosendahl, T., 2013. Modeling of vessel and equipment cost for the maintenance activities of an offshore tidal energy array, in: PRADS: The 12th Internation Symposium on Practical Design of Ships and Other Floating Structures, Changwon City, Korea. pp. 1-9.

[27] Lewis, M., Neill, S., Robins, P., Hashemi, M., 2015. Resource assessment for future generations of tidal-stream energy arrays. Energy 83, 403-415.

[28] Lewis, M., Neill, S., Robins, P., Hashemi, M., Ward, S., 2017. Characteristics of the velocity profile at tidal-stream energy sites. Renewable Energy 114, 258-272.

[29] Li, Y., Li, W., Liu, H., Lin, Y., Gu, Y., Xie, B., 2020. Indirect load measurements for large floating horizontal-axis tidal current turbines. Ocean Eningeering 198, 1-11.

[30] Lignarolo, L., Ragni, D., Ferreira, C., van Bassel, G., 2016. Experimental comparison of a wind-turbine and of an actuatordisc near wake. J. Renew. Sustain. Energ. 8, 26.

[31] Longuet-Higgins, M.S., 1953. Mass transport in water waves. Philosophical Transactions of the Royal Society A 245, 535-581.

[32] Lust, E.E., Luznik, L., Flack, K.A., Walker, J.M., Van Benthem, M.C., 2013. The influence of surface gravity waves on marine current turbine performance. International Journal of Marine Energy 3, 27-40.

[33] Luznik, L., Flack, K.A., Lust, E.E., Taylor, K., 2013. The effect of surface waves on the performance of a model tidal turbine. Renewable Energy 58, 108-114.

[34] McDowell, J., Jeffcoate, P., Khorasanchi, M., Johanning, L., Bruce, T., 2017. First steps towards a multi-parameter optimisation tool for floating tidal platforms - Assessment of an LCoE-based site selection methodology, pp. 1-10.

[35] Medici, D., 2005. Experimental Studies of Wind Turbine Wakes - Power Optimisation and Meandering. Ph.D. thesis. KTH Mechanics, Royal Institute of Technology, Sweden.

[36] Myers, L., Bahaj, A., 2010. Experimental analysis of the flow field around horizontal axis tidal turbines by use of scale mesh disk rotor simulators. Ocean Engineering 37, 218-227.

[37] Olczak, A., 2016. The influence of waves on tidal stream turbine arrays. Ph.D. thesis. University of Manchester.

[38] Orbital Marine Power, 2020. Orbital O2 2MW. website. https: //orbitalmarine.com/, last accessed 15.04.2020.

[39] Pierella, F., Sætran, L.R., 2010. Effect of initial conditions on flow past grids of finite extension, in: Proceedings of the 17th Australasian Fluid Mechanics Conference, Auckland, New Zealand. p. 4.

[40] Ransley, E., Brown, S., Xie, N., Greaves, D., Nicholls-Lee, R., Johanning, L., et al., 2018. Concept development for deployment of a modular, floating, tidal-stream device, in: Proceedings of the 3rd International Conference on Renewable Energies Offshore, Lisbon, Portugal.

[41] Ransley, E., Yan, S., Brown, S., Hann, M., Graham, D., Windt, C., et al., 2020. A blind comparative study of focused wave interactions with floating structures (CCP-WSI Blind Test Series 3). International Journal of Offshore and Polar Engineering 30, $1-10$.

[42] Santos-Mugica, M., Robles, E., Endegnanew, A.G., Tedeschi, A.G., Giebhardt, J., 2014. Grid integration and power quality 
testing of Marine Energy Converters: Research activites in the MaRINET project, in: 2014 Ninth International Conference on Ecological Vehicles and Renewable Energies (EVER), pp. 1-9.

[43] Sforza, P., Sheerin, P., Smorto, M., 1981. Three-dimensional wakes of simulated wind turbines. AIAA Journal 19, 1101-1107.

[44] Sheng, Q., Jing, F., Zhang, L., Zhou, N., Wang, S., Zhang, Z., 2016. Study of the hydrodynamic derivatives of vertical-axis tidal current turbines in surge motion. Renewable Energy 96, 366-376.

[45] Stokes, G.G., 1847. On the theory of oscillatory waves. Transactions of the Cambridge Philosophical Society 8, 441-455.

46] Tatum, S., Allmark, M., Frost, C., O'Doherty, D., Mason-Jones, A., O'Doherty, T., 2016. CFD modelling of a tidal stream turbine subjected to profiled flow and surface gravity waves. International Journal of Marine Energy 15, 156-174.

[47] Umeyama, M., 2011. Coupled PIV and PTV measurements of particle velocities and trajectories for surface waves following a steady current. Journal of Waterway, Port, Coastal and Ocean Engineering 137, 85-94.

[48] Vasquez, A., Iglesias, G., 2016. Grid parity in tidal stream energy projects: An assessment of financial, technological and economic LCOE input parameters. Technological Forecasting and Social Change 104, 89-101.

[49] Ward, S.L., Robins, P.E., Lewis, M.J., Iglesias, G., Hashemi, M.R., Neill, S.P., 2018. Tidal stream resource characterisation in progressive versus standing wave systems. Applied Energy 220, 274-285.

[50] Zhang, L., Wang, S., Sheng, Q., Jing, F., Ma, Y., 2015. The effects of surge motion of the floating platform on hydrodynamics performance of horizontal-axis tidal current turbine. Renewable Energy 74, 796-802.

[51] Zhou, Z., Benbouzid, M., Charpentier, J.F., Scuiller, F., Tang, T., 2017. Developments in large marine current turbine technologies - a review. Renewable and Sustainable Energy Reviews $71,852-858$. 